NBER WORKING PAPER SERIES

\title{
INTELLECTUAL PROPERTY RIGHTS AND INNOVATION: EVIDENCE FROM THE HUMAN GENOME
}

\author{
Heidi L. Williams \\ Working Paper 16213 \\ http://www.nber.org/papers/w16213 \\ NATIONAL BUREAU OF ECONOMIC RESEARCH \\ 1050 Massachusetts Avenue \\ Cambridge, MA 02138 \\ July 2010
}

I am very grateful to Wes Cohen, Joe Doyle, Dan Fetter, Matt Gentzkow, Claudia Goldin, Sam Kortum, Amanda Kowalski, Fiona Murray, Jesse Shapiro, Scott Stern, three anonymous referees, numerous seminar participants, and especially my $\mathrm{PhD}$ advisers David Cutler, Amy Finkelstein, and Larry Katz for comments. Several individuals from Celera, the Human Genome Project, and related institutions provided invaluable guidance, including Sam Broder, Peter Hutt, and particularly Mark Adams, David Altshuler, Bob Cook-Deegan, Eric Lander, Robert Millman, and seminar participants at the Broad Institute. David Robinson provided valuable assistance with the data collection. Financial support from NIA Grant Number T32-AG000186 to the NBER, NSF Grant Number 1151497, and the Center for American Political Studies at Harvard is gratefully acknowledged. The views expressed herein are those of the author and do not necessarily reflect the views of the National Bureau of Economic Research.

NBER working papers are circulated for discussion and comment purposes. They have not been peerreviewed or been subject to the review by the NBER Board of Directors that accompanies official NBER publications.

(C) 2010 by Heidi L. Williams. All rights reserved. Short sections of text, not to exceed two paragraphs, may be quoted without explicit permission provided that full credit, including $(\mathbb{C}$ notice, is given to the source. 
Intellectual Property Rights and Innovation: Evidence from the Human Genome

Heidi L. Williams

NBER Working Paper No. 16213

July 2010, Revised January 2013

JEL No. I10,I18,O3,O34

\begin{abstract}
$\underline{\text { ABSTRACT }}$
Do intellectual property (IP) rights on existing technologies hinder subsequent innovation? Using newlycollected data on the sequencing of the human genome by the public Human Genome Project and the private firm Celera, this paper estimates the impact of Celera's gene-level IP on subsequent scientific research and product development. Genes initially sequenced by Celera were held with IP for up to two years, but moved into the public domain once re-sequenced by the public effort. Across a range of empirical specifications, I find evidence that Celera's IP led to reductions in subsequent scientific research and product development on the order of 20 to 30 percent. Taken together, these results suggest that Celera's short-term IP had persistent negative effects on subsequent innovation relative to a counterfactual of Celera genes having always been in the public domain.
\end{abstract}

Heidi L. Williams

MIT Department of Economics

50 Memorial Drive

Building E52, Room 274C

Cambridge MA 02142-1347

and NBER

heidiw@mit.edu 
Innovation is a key driver of economic growth, but competitive markets may under-incentivize innovation due to the public good nature of ideas (Nelson, 1959, Arrow, 1962). Intellectual property (IP) rights, such as patents and copyrights, aim to incentivize innovation by allowing firms to capture a higher share of the social returns to their research investments. Traditional evaluations of the effectiveness of IP have focused on whether the prospect of obtaining IP rights stimulates the development of new technologies. However, in many markets technological change is cumulative, in the sense that product development results from several steps of invention and research. In markets where innovation is cumulative, the overall effectiveness of IP in promoting innovation also depends on a second, less studied question: do IP rights on existing technologies hinder subsequent innovation? The contribution of this paper is to provide empirical evidence on this second question by investigating how one form of IP on the human genome influenced subsequent scientific research and product development.

To fix ideas, suppose the firm Celera holds IP on a human gene, and that Pfizer discovers a genetic diagnostic test based on Celera's gene. Will Celera's IP discourage Pfizer from developing this test? In a perfect contracting environment with no transaction costs, Celera and Pfizer would negotiate a licensing agreement such that cumulative research is not hindered. However, transaction costs may cause licensing negotiations to break down, deterring some socially desirable research. While the theoretical literature on this question is well-developed (Scotchmer, 1991; Green and Scotchmer, 1995; Bessen, 2004), empirical evidence is scarce.

The empirical context analyzed in this paper is the sequencing of the human genome by the public Human Genome Project and the private firm Celera. The public effort began in 1990, and required that all sequenced genes be placed in the public domain. Celera's effort began in 1999, and ended in 2001 when Celera disclosed an incomplete draft genome. The public effort continued, and by 2003 had sequenced all genes in Celera's 2001 draft. Between 2001 and 2003, Celera used a contract law-based form of IP to protect genes sequenced by Celera but not yet sequenced by the public effort. This IP enabled Celera to sell its data for substantial fees, and required firms to negotiate licensing agreements with Celera for any resulting commercial discoveries - even though it was publicly known at the time that all of Celera's genes would be sequenced by the public effort, and thus be in the public domain, by 2003. Figure 1 summarizes a timeline of these key events.

How did Celera's gene-level IP influence subsequent scientific research and product development? To investigate this question, I construct a new dataset that tracks the timing of gene sequencing and Celera's IP across the human genome, linked to gene-level measures of scientific research and product development. Specifically, I trace cumulative innovation by compiling data on links between genes and phenotypes, which are observable traits or characteristics. For example, the link between variation on the HTT gene and Huntington's disease represents a genotype-phenotype link. For each gene, I collect data on publications investigating genotypephenotype links, on successfully generated knowledge about genotype-phenotype links, and on the development of gene-based diagnostic tests available to consumers 1

\footnotetext{
${ }^{1}$ Patent citations are a frequently-used measure of cumulative innovation (Jaffe, Trajtenberg and Henderson
} 
A simple cross-tabulation illustrates how this data can be used to investigate how Celera's IP influenced subsequent innovation. Table 1 compares subsequent innovation outcomes for Celera genes relative to non-Celera genes sequenced in the same year. Taken at face value, these data suggest that Celera's IP led to economically and statistically significant reductions in subsequent scientific research and product development. Celera genes had an average of 1.2 publications by 2009 , relative to 2.1 publications for non-Celera genes sequenced in the same year. About 3 percent of Celera genes were used in a gene-based diagnostic test as of 2009, relative to 5.4 percent of non-Celera genes sequenced in the same year.

These simple differences in means could reflect a negative effect of Celera's IP on subsequent research, or could reflect that Celera's genes had lower inherent potential for follow-on research. Because the institutional context suggests that selection bias could be a concern, I present estimates from two additional empirical tests that directly address selection. First, I restrict attention to within-gene variation in IP and test whether the removal of Celera's IP increased subsequent innovation. Second, I limit the sample to Celera genes and test for a link between the amount of time a gene was held with Celera's IP and subsequent innovation. These additional empirical tests appear to eliminate selection bias in the following sense: within the sample of $\sim 1,600$ Celera genes, proxies for the ex ante expected value of a gene do not predict the timing of when genes were re-sequenced by the public effort. The estimates from these two additional empirical tests are roughly the same magnitude as the estimates from the simple cross-tabulation: Celera's IP appears to have generated economically and statistically significant reductions in subsequent scientific research and product development, on the order of 20 to 30 percent.

This analysis does not evaluate the overall welfare consequences of Celera's entry, which may have been spurred by the prospect of obtaining IP. If Celera's entry spurred faster sequencing of the human genome, the overall timing of genome-related innovation likely shifted earlier in time, which would have had welfare gains even if Celera's IP in isolation hindered innovation. Rather, these results suggest that, holding Celera's entry constant, an alternative lump-sum reward mechanism may have had social benefits relative to Celera's chosen form of IP, ${ }^{2}$

This paper joins a handful of recent papers documenting evidence that IP may hinder subsequent innovation (Murray and Stern, 2007, Huang and Murray, 2009, Murray et al., 2008). Of particular note is the work of Murray et al. (2008), who analyze short-term IP the firm DuPont held on certain types of genetically engineered mice. Using a dataset of matched mouse-article pairs, the authors document that the removal of IP increased citations to scientific papers on affected mice by 20 to 40 percent relative to papers on unaffected mice - very similar to the magnitude of my estimates $3^{3}$

1993). However, by construction patent citations cannot measure cumulative innovation on non-patented technologies. The type of data constructed in this paper - measuring scientific research and product development directly, rather than via patent citations - is critical in enabling a test of how IP affects cumulative innovation.

${ }^{2}$ For example, under the patent buyout mechanism discussed by Kremer (1998), the public sector (or another entity) could have paid Celera some fee to "buy out" Celera's IP and place Celera genes in the public domain. See Kremer and Williams (2010) for further discussion of other alternative mechanisms for rewarding innovation.

3 Murray et al. (2008) also provide evidence, consistent with the model of Aghion, Dewatripont and Stein (2008), that IP reduces the diversity of scientific experimentation. 
The paper proceeds as follows. Section 1 provides a brief scientific background and a description of my data construction. Section 2 describes the empirical context, and Section 3 presents the empirical results. Section 4 links the empirical results back to previous theoretical and empirical analyses, in an attempt to interpret which types of transaction costs were likely most important in this context. Section 5 concludes.

\section{Preliminaries: Scientific primer and data construction}

This section provides a brief scientific background and describes my data construction. An appendix discusses my data construction in more detail.

\section{$1.1 \quad$ Scientific primer}

In classical genetics, a gene is defined as a unit of inheritance. Physically, a gene is defined as a stretch of deoxyribonucleic acid (DNA), which itself is a sequence comprised of four nucleotide bases - adenine $(A)$, cytosine $(C)$, guanine $(G)$, and thymine $(T) .4$ 'Sequencing the genome' refers to the process of determining the exact order of these nucleotide bases in the entire set of hereditary information for a given organism.

Genes affect health by generating proteins, which carry out functions in the human body. More precisely, genes code for messenger ribonucleic acids (mRNAs): a gene's sequence of nucleotide bases dictates the sequence of nucleotide bases in a generated mRNA. In turn, mRNAs code for proteins: an mRNA's sequence of nucleotide bases dictates what protein is generated. The intermediate step - mRNA - is important because a gene can code multiple proteins by coding multiple mRNAs. Reflecting this, sequencing the genome involved sequencing mRNAs.

Proteins induce variation in observable traits or characteristics of an organism, known as phenotypes. Known genotype-phenotype links can be combined with sequenced genes to form the basis for genetic tests. A gene can be involved in multiple genotype-phenotype links, and a genotype-phenotype link can involve more than one gene.

I use genes as my unit of analysis. Genes are stable scientific units, whereas the number of known mRNAs and known genotype-phenotype links in part reflects the amount of research invested in a given gene. Table 2 presents summary statistics on the gene-level data. My data include 27,882 currently known genes. The median length of a gene is around 17,000 nucleotide bases (Scherer, 2008).

\subsection{Tracking the public and private genome sequencing efforts}

I track the timing of the public sequencing effort using data from the US National Institutes of Health's RefSeq database. I define the year a gene was sequenced as the first year any mRNA

\footnotetext{
${ }^{4}$ In recent years the exact definition of a gene has become more complicated than this basic description; for a more detailed discussion see Snyder and Gerstein (2003). However, these subtleties are not important for the empirical analysis in this paper; my use of the term "gene" follows the definitions set out in the US National Institutes of Health's RefSeq database, which is used internationally as the standard for genome annotation.
} 
was disclosed for that gene. The median gene was sequenced in 2001 (Panel A of Table 2) 5

Istrail et al. (2004) compare Celera's 2001 draft genome with a snapshot of the public data. Building on their analysis, I am able to determine which genes were included in Celera's 2001 draft genome and the dates at which those genes eventually appeared in the public data. I define a Celera gene as a gene for which all known mRNAs were initially sequenced by Celera 6 Of the 27,882 currently known genes, 1,682 - about 6 percent - were held with Celera's IP for some amount of time (Panel A of Table 2). Because Celera's draft genome was disclosed in 2001, I code Celera genes as having been sequenced in 2001.

\subsection{Measuring scientific research and product development outcomes}

I collect four outcome variables: three measures of scientific research, and one measure of product development. My measures of scientific research are drawn from the Online Mendelian Inheritance in Man (OMIM) database, which aims to provide a comprehensive set of genotypephenotype records. OMIM entries are annotated with citations to published scientific papers. From these annotations, I collect data on the number of publications related to each gene in each year. I use publications from 2001 to 2009 as an outcome; on average, genes had 2 publications over that period, with a median of 0 (Panel B of Table 2).

OMIM assigns two classifications which I use as proxies for the level of scientific knowledge about genotype-phenotype links. All genes involved in at least one genotype-phenotype link classified by OMIM as meeting a high level of scientific certainty are coded as having a "known, certain phenotype." The set of genes classified by OMIM as meeting a lower threshold for scientific certainty (including those meeting the higher threshold) are coded as having a "known, uncertain phenotype." I observe the former measure as of 2009, and the latter measure annually. As of 2009, forty-five percent of genes have a known, uncertain phenotype link, and 8 percent have a known, certain phenotype link (Panel B of Table 2).

My measure of product development is drawn from GeneTests.org, a self-reported, voluntary listing of US and international laboratories offering genetic testing. Although not comprehensive, GeneTests.org is the most frequently referenced genetic testing directory (Uhlmann and Guttmacher, 2008). I construct an indicator for whether each gene is used in any genetic test as of 2009. As of 2009, 6 percent of genes were used in a genetic test (Panel B of Table 2) .7 $^{7}$

\subsection{Data construction: An example}

A brief example may help to clarify my data construction. The mRNA NM_032753.3 first appeared in RefSeq in 2001, and was never held with Celera's IP. This is the only known mRNA for the RAX2 gene. I define RAX2 as sequenced in 2001, and never held by Celera.

\footnotetext{
${ }^{5}$ The mean for this variable is left-censored, because 1999 is the first year coded in the RefSeq database.

${ }^{6}$ The mean number of known mRNAs per gene is 1.67 , and the median is 1 . Thus, alternative definitions such as the share of known mRNAs that were Celera mRNAs, or an indicator for whether any mRNA on the gene was a Celera mRNA - are identical for the majority of genes.

${ }^{7}$ These tests can be developed quite quickly; Cho et al. (2003) note it may only take weeks or months to go from a research finding that a particular genetic variant is associated with a disease to a clinically validated test.
} 
OMIM references RAX2 in two genotype-phenotypes, first appearing in 2006. Both reference a 2004 publication in Human Molecular Genetics, and are classified by OMIM as known, certain phenotypes. First, RAX2 is linked to age-related macular degeneration, a medical condition arising in older adults that destroys the type of central vision needed for common tasks such as driving, facial recognition, and reading. Second, RAX2 is linked to cone-rod dystrophy, an eye disease tending to cause vision loss. I define RAX2 as having one publication in 2004; in a known, uncertain phenotype link as of 2006; and in a known, certain phenotype link as of $20098^{8}$

GeneTests.org lists several testing facilities offering a genetic test for RAX2's link to agerelated macular degeneration (including some academic medical centers as well as the for-profit firm Quest Diagnostics). There are no listings for genetic tests for RAX2's link to cone-rod dystrophy. I define RAX2 as being used in a diagnostic test as of 2009.

\subsection{Linking scientific research and product development}

The prior empirical literature investigating how IP affects subsequent innovation has been constrained to examine only publication-related outcome variables, whereas in this paper I am able to trace how IP affected the availability of commercial products. A priori, this distinction is important: if academic and public researchers face higher incentives to disclose the results of their research than do private researchers, and if IP induces an increase in the share of research done by private researchers, then observed differences in publications could in part be explained by differences in disclosure $9^{9}$ However, my product development outcome - diagnostic test availability - should be invariant with respect to disclosure preferences of researchers.

Panel A of Figure 2 presents one set of descriptive statistics illustrating that, in my data, scientific research and product development are strongly related. The dashed line ("no test as of 2009") plots the empirical cumulative distribution function of the number of publications between 1970-2000 for genes that do not have a diagnostic test available as of 2009 10 The solid line ("test as of 2009") plots the empirical cumulative distribution function of the number of publications between 1970-2000 for genes that do have a diagnostic test available as of 2009 . Virtually all genes not used in diagnostic tests had 10 or fewer publications, whereas about 70 percent of genes used in diagnostic tests had more than 10 publications.

Panel B of Figure 2 presents an alternative set of descriptive statistics illustrating a similar point. The dashed line plots the distribution of genes, ordered by the number of publications between 1970-2000; consistent with the summary statistics presented in Table 2, most genes have zero publications. The solid line plots the share of genes with a diagnostic test for each number of publications. The share of genes with a diagnostic test increases roughly monotonically with the number of publications between 0 and around 30 publications, and then continues to increase

\footnotetext{
${ }^{8}$ As detailed above, I only observe the "known, certain phenotype" measure as of 2009.

${ }^{9}$ Of course, disclosure itself presumably has social value, and to the extent that IP induces reductions in disclosure this effect is also relevant in measuring the welfare effects of IP. Moon (2011) provides an empirical study of disclosure in the context of genetic research. Analyzing the discovery of a genotype-phenotype link in an event study framework, he shows that non-academic research organizations become less likely to publish relative to universities after the discovery of a phenotype link.

${ }^{10}$ There are very few pre-1970 publications cited in the OMIM data.
} 
more slowly above that point. These data suggest that the number of publications is strongly related to the probability that a diagnostic test is available.

\section{Empirical context}

This section briefly reviews the institutional context relevant for the empirical analysis ${ }^{11}$

\subsection{Timeline of sequencing efforts}

The public sequencing effort - the Human Genome Project - was launched in 1990, and originally aimed to finish sequencing the entire genome by 2005 (Collins and Galas, 1993). In May 1998, Celera - a new firm led by scientist Craig Venter - formed with the intention to sequence the entire human genome within three years (Venter et al., 1998). The public effort subsequently announced a revised plan to complete its sequencing efforts by 2003 (Collins et al., 1998), and to release an earlier "draft" sequence of the human genome (Pennisi, 1999) 12 Departing from its previous goal of producing a near-perfect sequence, the aim of this draft sequence was to place most of the genome in the public domain as soon as possible. The two efforts jointly published draft genomes in February 2001, the public effort in Nature (Lander et al., 2001) and Celera in Science (Venter et al. 2001). 13 Celera's sequencing effort stopped with this publication, whereas the public effort continued and was declared complete in April 2003 (Wade, 2003).

\subsection{Intellectual property: The Bermuda rules and Celera's IP}

As of 1996, genes sequenced by the public effort were covered by the "Bermuda rules," requiring data to be posted on an open-access website within twenty-four hours of sequencing ${ }^{14}$ The stated goal was “...to encourage research and development and to maximize [the data's] benefit to society." 15 Eisenberg (2000) argues the Bermuda rules also aimed to discourage gene patenting.

Between 2001 and 2003, Celera used a contract law-based form of IP to protect genes that had been sequenced by Celera but not yet sequenced by the public effort. Celera's IP had several key features ${ }^{16}$ First, Celera's data were 'disclosed' in 2001 (Venter et al. 2001), in the sense that any individual could view data on the assembled genome through Celera's website, or by obtaining a free data DVD from the company 17 Academic researchers were free to use Celera's

\footnotetext{
${ }^{11}$ For more details, see Cook-Deegan $\left.\sqrt{1994}\right)$, Shreeve $\left.\sqrt{2005}\right)$, Sulston and Ferry $(2002)$, and Venter $(2007)$.

${ }^{12}$ Many observers attribute this scale-up to Celera's entry (Marshall 1998).

${ }^{13}$ Celera and a few "early subscriber" firms had access to intermediate data updates during late 1999 and 2000 , but my understanding is that the vast majority of Celera's data were first released in the 2001 draft genome.

${ }^{14}$ In 1996, the heads of the largest labs involved in the public effort agreed at a Bermuda-based meeting to these rules as a set of guidelines for data sequenced under the public effort. The Bermuda Rules replaced a US policy that data be made available within six months (Marshall, 2001).

${ }^{15}$ These rules are described in various policy statements by the US National Human Genome Research Institute ||(NHGRI). Non-adherence was expected to result in black marks on future grant reviews (Marshall, 2001).

${ }^{10}$ For details, see Celera's data access agreement (Science Online, 2001), and Celera's DVD user agreement. I am very grateful to Mike Meurer, Robert Millman (then-Chief IP Counsel at Celera from 1999-2002), and Ben Roin for discussions on Celera's IP, but of course none of them is responsible for any errors in my descriptions.

${ }^{17}$ Viewing the data or obtaining the DVD required agreeing not to commercialize or redistribute the data.
} 
data for non-commercial research and academic publications. Second, by placing restrictions on redistribution, Celera was able to sell its data to larger institutions - including pharmaceutical companies, universities, and research institutes. Although the terms of specific deals were private, Service (2001) reports that pharmaceutical companies were paying between $\$ 5$ million and $\$ 15$ million a year, whereas universities and nonprofit research organizations were paying between $\$ 7,500$ and $\$ 15,000$ for each lab given access to the data. Third, any researcher wanting to use the data for commercial purposes was required to negotiate a licensing agreement with Celera. Celera was able to charge these data access and licensing fees even though all available accounts suggest it was publicly known in 2001 that all of Celera's genes would be re-sequenced by the public effort, and thus move into the public domain, by 2003. Shreeve (2005) quotes Craig Venter as saying: "Amgen, Novartis, and now Pharmacia Upjohn have signed up knowing damn well the data was going to be in the public domain in two years anyways. They didn't want to wait for it." In addition to this short-term IP, Shreeve (2005) documents that Celera was actively pursuing gene patent applications for genes in its database; ex post most of these applications were not granted patents, but given the contemporaneous and subsequent policy uncertainty surrounding gene patenting it is difficult to know what researchers' expectations were at the time 18 Beyond database sales and licensing revenues, Celera's business model also included in-house research and profits from genes granted patents (Service, 2001). Celera eventually grew into a healthcare firm that develops and manufactures gene-based technologies.

\subsection{Sequencing strategies: Implications for selection into Celera's IP}

The public sequencing effort was a large consortium that, for the purposes of this paper, can be conceptualized as two distinct efforts. A 'targeted' effort focused on sequencing genes with known medical value, such as the gene linked to Huntington's disease. A 'large-scale' effort focused on the same type of large-scale sequencing undertaken by Celera. Large-scale sequencing by both Celera and the public effort relied on the shotgun sequencing method, in which DNA is randomly broken up into small segments that are sequenced and re-assembled (Lander et al., 2001). From an empirical perspective, shotgun sequencing should have introduced some effectively random variation in whether genes were initially sequenced by Celera or by the public effort.

The vast majority of genes were sequenced under the large-scale public effort, which started in mid-1999 (Lander et al., 2001). However, because the targeted public effort focused on sequencing genes that had high ex ante expected medical value, we expect that Celera genes - on average - will be negatively selected in the sense of having a lower inherent potential for follow-on research. This selection is important, because it implies that the simple crosstabulation presented in Table 1 could be misleading. This concern motivates the construction of empirical measures that proxy for the ex ante expected value of each gene in order to empirically investigate patterns of selection in my data.

\footnotetext{
${ }^{18}$ What the US Patent and Trademark Office has allowed to be covered by a "gene patent" has changed dramatically over time; see, e.g. National Academy of Sciences $(2006)$. There has also been substantial variation over time in the judicial enforcement of existing gene patents.
} 
Based on discussions with scientists, one reasonable proxy for the ex ante expected value of a gene is the number of scientific papers published about the gene before it was sequenced. For example, a long scientific literature has documented evidence that Huntington's disease has a genetic basis. Many of these papers were published prior to the development of gene sequencing techniques, and the evidence from these papers likely led scientists to target the sequencing of genes related to Huntington's disease more than genes related to conditions that were less well-understood.

Figure 3 uses data on the number of OMIM publications about a gene from 1970 to 2000 to investigate selection into Celera's IP. The solid line ( "all genes") plots the difference in mean publications on Celera genes and mean publications on non-Celera genes in each year from 1970 to 2000. All observations are less than zero, providing empirical evidence consistent with the type of selection I described: genes initially sequenced by the public effort had higher ex ante expected value than genes initially sequenced by Celera. One formal test for such selection is to use an ordinary-least-squares model to predict the gene-level "celera" indicator as a function of count variables for publications in each year from 1970-2000. In the full sample, the $p$-value from an $F$-test for joint significance is less than 0.001 .

Unfortunately, I do not observe which genes were sequenced by the targeted public effort, so I cannot directly exclude those genes from the sample. As an alternative, I limit the comparison group of non-Celera genes to those sequenced in 2001 (the year Celera's draft genome was disclosed). Because the number of genes sequenced under the targeted public effort was likely small in 2001 relative to the number of genes sequenced under the large-scale effort, selection should be reduced in this sample. The dashed line in Figure 3 ( "genes sequenced in 2001") suggests this sample restriction reduces but does not eliminate observed selection. In this restricted sample, the $p$-value from an $F$-test for joint significance is 0.033 . Selection will thus be a concern in my cross-section estimates; this motivates two additional empirical tests that address selection.

My second and third empirical tests rely on variation in the timing of when Celera genes were resequenced by the public effort (either 2002 or 2003). The dotted line in Figure 3 ( "Celera genes") plots the difference in mean publications on Celera genes resequenced in 2003 and mean publications on Celera genes resequenced in 2002, in each year from 1970 to 2000. Here, I find no evidence of selection: predicting a gene-level indicator for being resequenced in 2003 as a function of these count variables for publications in each year, the $p$-value from an $F$-test for their joint significance is 0.169 . This result suggests that, post-2001, the public effort was either not targeting or not successfully targeting the resequencing of more valuable Celera genes. This evidence supports the validity of my second and third empirical tests.

\section{$3 \quad$ Empirical results}

\subsection{Cross-section estimates}

The basic comparison underlying my cross-section estimates can be a presented in a simple cross-tabulation. Table 1 compares subsequent innovation outcomes for Celera genes and for 
non-Celera genes sequenced in 2001. These data suggest Celera genes have lower levels of subsequent scientific research and product development relative to non-Celera genes sequenced in the same year. For example, about 3 percent of Celera genes were used in a gene-based diagnostic test in 2009, relative to 5.4 percent of non-Celera genes sequenced in the same year.

The concern with interpreting these simple differences in means is that they could reflect a negative effect of Celera's IP on subsequent research, or could instead reflect selection if Celera's genes had lower inherent potential for follow-on research. In order to address this concern, Table 3 formalizes the basic comparison from Table 1 in a regression framework that allows me to investigate the robustness of these patterns. For gene $g$, I estimate the following:

$$
(\text { outcome })_{g}=\alpha+\beta(\text { celera })_{g}+\lambda^{\prime}(\text { covariates })_{g}+\varepsilon_{g} \text {. }
$$

The coefficient on the "celera" variable is the main estimate of interest. I show estimates from ordinary-least-squares (OLS) models, and report heteroskedasticity-robust standard errors 19

Column (1) of Table 3 replicates the cross-tabulation results on the full sample, controlling for year of disclosure but no other covariates ${ }^{20}$ Column (2) of Table 3 includes a set of count variables for the number of publications on each gene in each year from 1970 to 2000 . We saw in Section 2.3 that Celera genes looked less valuable than non-Celera genes based on these proxies for ex ante expected value. As expected, including these variables as covariates reduces the magnitudes of the point estimates. Column (3) limits the sample to genes with non-missing data on location variables $(n=16,485)$, and investigates whether the estimates are sensitive to conditioning on detailed location variables. This robustness check addresses the possibility that scientists may have targeted their sequencing efforts based on a gene's ex ante known location on the genome. For example, certain chromosomes (such as chromosome 19) were estimated to be more "gene-rich" than others, and scientists may have targeted the sequencing of such chromosomes. To test for this possibility, I collect detailed variables on both types of gene location descriptors used by geneticists (cytogenetic location and molecular location). The estimates in Column (3) are quite similar in magnitude to the estimates in Column (2).

For brevity, I focus on interpreting the magnitudes of the point estimates in Column (1). The estimate in Panel A implies Celera genes had about 0.88 fewer publications from 2001 to 2009 , a decline on the order of $40 \%$ of the mean number of publications for genes over that time period. The estimate in Panel B implies a 16 percentage point reduction in the probability of having a known, uncertain phenotype link, a decline on the order of $35 \%$ relative to the sample mean. The estimate in Panel $\mathrm{C}$ implies a 2.7 percentage point reduction in the probability of having a known, certain phenotype link, a decline on the order of $33 \%$ of the sample mean. The

\footnotetext{
${ }^{19}$ As a robustness check, in Appendix Table B.1 I present estimates from proportional models that are analogous to the estimates in Table 3 quasi-maximum likelihood Poisson models for publications, and logit models for the three binary outcomes.

${ }^{20}$ There are two ways to control for variation in innovation outcomes across genes as of 2009 that is a function of the year in which the genes were sequenced: limiting the sample to the set of genes sequenced in 2001, or using the full sample but including indicator variables to control for year of disclosure. Because all Celera genes were sequenced in 2001, the "celera" variable only varies in 2001. Hence, re-estimating the specification in Column (1) on the sub-sample of genes sequenced in 2001 estimates identical coefficients. I use the full sample in these robustness checks because the additional non-Celera genes are useful for identifying the covariates.
} 
estimate in Panel D implies a 2.3 percentage point reduction in the probability of a gene being used in any currently available diagnostic test, a decline on the order of $38 \%$ of the sample mean. One way to interpret the magnitudes of these differences in means is the following: if Celera genes had counterfactually had the same rate of subsequent innovation as non-Celera genes, there would have been 1,400 additional publications between 2001 and 2009, and 40 additional diagnostic tests as of $2009{ }^{21}$ The magnitudes of the estimated coefficients decline in magnitude when I add additional control variables, and the estimates in Columns (2) and (3) are on the order of 20 to 30 percent of the sample means.

Of course, despite my attempts to control for selection, the lingering concern is that these estimates could be driven by non-random selection into Celera's IP. Sections 3.2 and 3.3 present results from my second and third empirical tests, which address selection more directly.

\subsection{Panel estimates}

My second empirical test investigates whether the the removal of Celera's IP affected within-gene flow measures of subsequent innovation. For gene-year gy, I estimate the following:

$$
(\text { outcome })_{g y}=\alpha+\delta_{g}+\gamma_{y}+\beta(\text { celera })_{g y}+\varepsilon_{g y} .
$$

The "celera" variable is now an indicator for whether gene $g$ had been sequenced only by Celera as of that year. This "celera" variable varies within genes over time, and a transition from 1 to 0 represents the removal of Celera's IP from a given gene. Year fixed effects control for year-specific shocks that are common across genes, such as annual changes in the level of research funding available from public sector agencies. Gene fixed effects control for time-invariant differences across genes, such as a gene's inherent commercial potential. I limit the years in the sample to 2001-2009, focusing on the time period in which all Celera genes had been sequenced, but vary in their IP status over time ${ }^{22}$ I show estimates from OLS models and report heteroskedasticityrobust standard errors clustered at the gene level.

Table 4 presents estimates from the panel specification. Columns (1) and (2) are analogous to the cross-section specifications from Table 3 . both control for year fixed effects, Column (1) includes indicator variables for the year of disclosure, and Column (2) adds count variables for the number of publications in each year from 1970 to 2000. Column (3), my preferred

\footnotetext{
${ }^{21}$ I calculated these figures using non-Celera genes sequenced in 2001 as my counterfactual, as in Table 1, as follows. Between 2001 and 2009, there were 8,118 publications on the cohort of genes sequenced in 2001, with an average of 2.116 publications for non-Celera genes and an average of 1.239 publications for Celera genes. If we assume that Celera genes had attained the non-Celera average number of publications, there would instead have been 9,592 publications. Hence, Celera's IP led to around 1,400 fewer publications between 2001 and 2009 $(9,592-8,118 \approx 1,400)$. Undertaking a similar calculation for diagnostic tests, the number of genes sequenced in 2001 with a diagnostic test available as of 2009 was 204, and the probability of having a diagnostic test was 0.030 for Celera genes and 0.054 for non-Celera genes. If Celera genes had attained the non-Celera average probability of being used in a diagnostic test, there would instead have been 245 diagnostic tests as of 2009. Hence, Celera's IP led to around 40 fewer diagnostic tests as of $2009(245-204 \approx 40)$.

${ }^{22}$ As noted in Section 2.1. Celera's sequencing began in 1999, and its draft genome was disclosed in 2001. My understanding is that the vast majority of Celera's data were first released in the 2001 draft genome, but I do not observe the timing of sequencing from 1999-2001. In the absence of such data, I limit my panel specification to include the years 2001-2009 since prior to 2001 I do not know whether or not Celera genes had yet been sequenced.
} 
specification, retains the year fixed effects but replaces the time-invariant covariates with gene fixed effects.

Panel A of Table 4 reports estimates for the gene-year publications outcome. As in the cross-section specification, adding the publication variables does affect the estimated effect of Celera's IP. In addition, replacing the time-invariant covariates with gene fixed effects further reduces the magnitude of the estimated effect. That said, the magnitudes of the coefficients in Columns (2) and (3) are broadly similar, which I interpret as suggestive evidence that the cross-section controls are at least somewhat effective in controlling for gene-specific variation in the publications outcome. In terms of magnitudes, the coefficient in Column (3) in Panel A of Table 4 suggests Celera's IP was associated with 0.11 fewer publications per year, a decline on the order of $45 \%$ of the sample mean.

Panel B of Table 4 reports analogous estimates for the gene-year indicator for a gene having any known, uncertain phenotype link as of that year. The coefficient in Column (3) suggests Celera's IP was associated with a 8.3 percentage point reduction in the probability that a gene had a known, uncertain phenotype link, a decline on the order of $22 \%$ of the sample mean.

To explore the timing of the estimated effects, Figure 4 presents graphical versions of the following event study specification:

$$
(\text { outcome })_{g y}=\alpha+\delta_{g}+\gamma_{y}+\Sigma_{z} \beta_{z}(\text { celera })_{g} * 1(z)+\varepsilon_{g y} .
$$

On the $x$ axes are years $z$ relative to a "zero" relative year that marks the last year the gene was held with Celera's IP (that is, year 1 marks the first year the gene was in the public domain). The dotted lines show 95 percent confidence intervals.

Panel A of Figure 4 presents results for the gene-year level publications outcome. These estimates suggest that in the first year a gene enters the public domain ( $t=1$ on the graph), there is a discrete level shift in the flow of publications related to that gene, which remains relatively constant through the end of my data. In theory, the panel estimates in Table 4 could have been driven by short-term shifts in the timing of when research takes place that may or may not have persistent effects on welfare. In practice, the results show no clear "bunching" of publications that would be predicted by stories in which researchers strategically wait until IP is removed to publish scientific papers.

Panel B of Figure 4 presents results for the gene-year level indicator for a gene having any known, uncertain phenotype link. This outcome increases in the first year a gene enters the public domain ( $t=1$ on the graph), and continues to increase through the end of my data.

\subsection{Focusing on Celera genes}

Figure 5 presents results from my third empirical test. I limit the sample to include only Celera genes, and rely solely on variation in how long genes were held with Celera's IP - that is, whether the Celera gene was re-sequenced by the public effort in 2002 ( $N=1,047$; "public in 2002") or in 2003 ( $N=635$; "public in 2003"). The evidence presented in Section 2.3 and Figure 3 suggests that the year in which Celera genes were re-sequenced by the public effort cannot be predicted 
with gene-level observables. Hence, this analysis should provide a clean test for investigating the effect of being held with Celera's IP for one additional year.

Figure 5 presents means by year for the two panel outcome variables. As expected, the mean levels of both outcome variables are quite similar across the "public in 2002" and "public in 2003" groups in 2001, when both sets of genes were held with Celera's IP. Panel A shows that Celera genes re-sequenced in 2002 saw a relative uptick in publications in that year, while Celera genes re-sequenced in 2003 show a similar uptick in 2003. Flow of scientific effort into these two cohorts of genes appears to have converged over time: although the difference in means in 2002 is statistically significant at the 10 percent level, mean differences in other years are not statistically significant.

Panel B shows that Celera genes re-sequenced in 2002 saw a relative increase in the probability of having a known, uncertain genotype-phenotype link in 2002. However, rather than the "public in 2003" group catching up with their "public in 2002" counterparts one year later, the "public in 2003" group has persistently lower levels of this outcome variable through the end of my data. The difference in means is statistically significant in 2003 (at the 10 percent level), 2006 (at the 10 percent level), 2007 (at the 5 percent level), and 2008 (at the 5 percent level).

The results in Figure 5 suggest that although the flow of scientific effort into these two cohorts of genes (as measured by annual publications) converged over time, the average stock of scientific knowledge about genes in these two cohorts (as measured by having a known, uncertain phenotype) did not converge. I test this formally by estimating whether the mean of the "public in 2002" cohort in year $t$ is statistically distinguishable from the mean of the "public in 2003" cohort in year $t+1$; in no year can I reject the null that those means are equal. That is, I cannot reject a model in which an additional year of Celera's IP induces a permanent loss of one year of research. These results provide clear evidence that even very temporary forms of intellectual property - here, lasting only one year - can have persistent effects on subsequent innovation.

\section{What kinds of transaction costs were relevant?}

Return to the example from the introduction: suppose Pfizer discovers a gene-based diagnostic test that requires licensing one of Celera's genes. Would Celera's IP impede Pfizer's research?23 The empirical evidence in this paper suggests it would, which implies that some form of transaction costs hindered licensing negotiations over Celera's IP. In evaluating which potential sources of transaction costs were most likely relevant, both Celera's short-term IP and the expectation that Celera was pursuing patent applications on their genes are relevant.

In a perfect contracting environment with no transaction costs, Celera and Pfizer would negotiate a licensing agreement such that cumulative research is not hindered. Consider the model of Green and Scotchmer (1995). Licensing agreements can occur at two stages: ex ante, before Pfizer invests in the diagnostic test, or ex post, after Pfizer has invested in the test.

\footnotetext{
${ }^{23}$ Beyond the references in the introduction (Scotchmer, 1991, Green and Scotchmer, 1995, Bessen, 2004), see also the discussions in Merges and Nelson (1990), Heller and Eisenberg (1998), and Shapiro (2000).
} 
The key distinction is whether Pfizer has sunk its research costs at the time of the licensing negotiation. The Green and Scotchmer (1995) framework delivers a strong prediction that ex ante licenses are optimal and will always be negotiated. When negotiating ex ante, Pfizer has a credible threat not to invest unless Celera is willing to share a positive fraction of the diagnostic test profits. When negotiating ex post, Pfizer has diminished bargaining power and faces a potential holdup problem.

Despite this strong theoretical prediction, transaction costs may prevent ex ante licensing agreements from being successfully negotiated. For example, the Green and Scotchmer (1995) framework assumes symmetric information, but in practice Celera may not have known Pfizer's cost of developing its gene-based diagnostic test. Bessen (2004) explores the implications of this type of private information in the Green and Scotchmer (1995) framework, showing that private information may cause negotiations to break down, deterring some socially desirable research.

Empirically, only a small share of licensing agreements appear to be set ex ante. Anand and Khanna (2000) document that in SIC28 (chemicals and pharmaceuticals), only $23 \%$ of licensing agreements were set ex ante. Consistent with this data, Celera's data access agreement (Science Online, 2001), Celera's DVD user agreement, and my informal discussions with academic and commercial researchers all suggested Celera's licensing agreements were frequently if not always negotiated ex post rather than ex ante.

Celera could have avoided transaction costs by conducting in-house research; indeed, Celera developed and manufactured several gene-based technologies. However, ideas in this market were likely scarce in the sense of Scotchmer (1991): Celera's scientists did not know how to develop the full set of possible subsequent innovations. Taken together, this suggests that a scarcity of ideas together with asymmetric information about the costs of development may have generated a first source of transaction costs.

A second source of potential transaction costs is a version of the classic disclosure problem (Arrow, 1962), highlighted by Gallini and Wright (1990) and Gans and Stern (2000). To negotiate a licensing agreement with Celera, Pfizer had to disclose its idea. Because Celera was developing gene-based technologies, Celera had a credible threat to engage in imitative R\&D. Either the expectation of Celera's bargaining position, or the actual impact of Celera's bargaining power in licensing negotiations, may have generated a second source of transaction costs.

A final source of potential transaction costs is uncertainty over the academic research exemption. Formally, Celera placed no restrictions on academic research. However, for at least two reasons academic researchers may have nonetheless been deterred from using Celera's data. First, informal discussions with academic scientists suggested they faced uncertainty over some of Celera's contractual terms. For example, one scientist I spoke with expressed uncertainty over whether the restrictions on redistribution implied she could not share Celera's data with her graduate students. Because accessing the data required agreeing to Celera's terms of use, perceived litigation risks may have deterred research even by academics who solely wanted to use the data for non-commercial research. Second, given that the boundary between academic and commercial research is often not clearly delineated - perhaps particularly for biomedical 
research (Cohen and Walsh, 2008) - the 'exemption' for academic research may not have been clear in practice. Celera's sequencing took place during the biotech boom, when many academics were doing research with an eye towards commercial applications. Celera's IP may have discouraged that type of academic research even in the absence of formal restrictions on academic publications.

\section{Concluding remarks}

Intellectual property (IP) is a widely-used policy lever for promoting innovation, yet relatively little is known about how IP on existing technologies affects subsequent innovation. The sequencing of the human genome provides a useful empirical context, generating variation in IP across a relatively large group of ex ante similar technologies. Across a range of empirical specifications, I find evidence that Celera's IP led to reductions in subsequent scientific research and product development on the order of 20 to 30 percent.

A caveat to this interpretation of these results is that if innovation inputs are scarce, my estimates could reflect the substitution of innovative effort away from Celera genes towards non-Celera genes (as opposed to a net decrease in total innovation over the set of all genes) ${ }^{24}$ Looking at a broad set of academic biomedical researchers, surveys by Walsh, Cho and Cohen (2005) and Walsh, Cohen and Cho (2007) suggest some substitution is relevant: restricted access to tangible research inputs (including information, data, and software) appears to shift scientists' research project choices. If substitution is relevant and researchers optimally choose their line of research in the absence of IP, quantifying the welfare costs of IP on cumulative innovation requires estimating the cost of distorting research towards sub-optimal projects. If more socially valuable technologies are more likely to be held with IP, these welfare costs could be substantial.

While Celera's gene-level IP did not depend on patent protection, the evidence in this paper is related to the ongoing legal controversy surrounding patents on human genes 25 Echoing the broader debate on patents, proponents argue that gene patents incentivize investment in gene-related technologies, while opponents argue that gene patents stifle subsequent product development and restrict patients' access to gene-related technologies 26 To the best of my knowledge, there exists no direct evidence on how gene patents have affected subsequent product development. Moreover, the overall welfare consequences of gene patents - and patents

\footnotetext{
${ }^{24}$ A priori, the relevance of substitution depends on whether inputs to gene-related research should be considered relatively fixed or relatively flexible.

${ }^{25}$ Two recent court cases are relevant. First, Association for Molecular Pathology v. Myriad Genetics (formerly Association for Molecular Pathology v. U.S. Patent and Trademark Office) is a lawsuit challenging the validity of gene patents held by the firm Myriad Genetics related to the BRCA1 and BRCA2 genes. In November 2012, the US Supreme Court agreed to hear the AMP v. Myriad case, with a decision expected before July 2013. Second, Mayo Collaborative Services, dba Mayo Medical Laboratories, et al. v. Prometheus Laboratories Inc. was a lawsuit challenging the patentability of diagnostic tests with implications for the patentability of gene-based diagnostic tests. The US Supreme Court handed down a unanimous decision in Mayo v. Prometheus in March 2012, upholding the District court decision that declared Prometheus's diagnostic test not patent eligible, and reversing the US Court of Appeals for the Federal Circuit.

${ }^{26}$ Opponents of gene patents have also argued that such patents may be invalid on the grounds that DNA is not patentable subject matter.
} 
more generally - depend on the trade-off between ex ante incentives for innovation, the ex post costs of restricting patients' access to technologies, and any potential effects of IP on subsequent innovation. From a policy perspective, the evidence in this paper informs this gene patent debate by documenting that - at least for some forms of intellectual property - getting the incentives "right" for subsequent innovators is quantitatively important for encouraging subsequent scientific research and product development. 


\section{References}

Aghion, Philippe, Mathias Dewatripont, and Jeremy Stein, "Academic freedom, private-sector focus, and the process of innovation," RAND Journal of Economics, 2008, 39 (3), 617-635.

Anand, Bharat and Tarun Khanna, "The structure of licensing contracts," Journal of Industrial Economics, 2000, 48 (1), 103-135.

Arrow, Kenneth, "Economic welfare and the allocation of resources for invention," in Richard Nelson, ed., The Rate and Direction of Inventive Activity, Princeton University Press, 1962.

Bessen, James, "Holdup and licensing of cumulative innovations with private information," Economics Letters, 2004, 82 (3), 321-326.

Cho, Mildred, Samantha Illangasekare, Meredith Weaver, Debra Leonard, and Jon Merz, "Effects of patents and licenses on the provision of clinical genetic testing services," Journal of Molecular Diagnostics, 2003, 5 (1), 3-8.

Cohen, Wesley and John Walsh, "Real impediments to academic biomedical research," in Josh Lerner and Scott Stern, eds., Innovation Policy and the Economy Volume 8, University of Chicago Press, 2008.

Collins, Francis and David Galas, "A new five-year plan for the U.S. Human Genome Project," Science, 1993, 262 (5130), 43-46.

_, Ari Patrinos, Elke Jordan, Aravinda Chakravarti, Raymond Gesteland, LeRoy Walters, the members of the DOE, and NIH planning groups, "New goals for the US Human Genome Project: 1998-2003," Science, 1998, 282 (5389), 682-689.

Cook-Deegan, Robert, The Gene Wars: Science, Politics, and the Human Genome, W. W. Norton \& Company, 1994.

Eisenberg, Rebecca, "Genomics in the public domain: Strategy and policy," Nature Reviews Genetics, 2000, 1 (1), 70-74.

Gallini, Nancy and Brian Wright, "Technology transfer under asymmetric information," RAND Journal of Economics, 1990, 21 (1), 147-160.

Gans, Joshua and Scott Stern, "Incumbency and R\&D incentives: Licensing the gale of creative destruction," Journal of Economics $\mathscr{E}$ Management Strategy, 2000, 9 (4), 485-511.

Green, Jerry and Suzanne Scotchmer, "On the division of profit in sequential innovation," $R A N D$ Journal of Economics, 1995, 26 (1), 20-33.

Heller, Michael and Rebecca Eisenberg, "Can patents deter innovation? The anticommons in biomedical research," Science, 1998, 280 (5364), 698-701.

Huang, Kenneth and Fiona Murray, "Does patent strategy shape the long-run supply of public knowledge: Evidence from human genetics," Academy of Management Journal, 2009, 52 (6), 11981221.

Istrail, Sorin et al., "Whole-genome shotgun assembly and comparison of human genome assemblies," Proceedings of the National Academy of Sciences, 2004, 101 (7), 1916-1921.

Jaffe, Adam, Manuel Trajtenberg, and Rebecca Henderson, "Geographic localization of knowledge spillovers as evidenced by patent citations," Quarterly Journal of Economics, 1993, 108 (3), $577-598$.

Kremer, Michael, "Patent buyouts: A mechanism for encouraging innovation," Quarterly Journal of Economics, 1998, 113 (4), 1137-1167. 
_ and Heidi Williams, "Incentivizing innovation: Adding to the toolkit," in Josh Lerner and Scott Stern, eds., Innovation Policy and the Economy Volume 10, University of Chicago Press, 2010, pp. 117 .

Lander, Eric et al., "Initial sequencing and analysis of the human genome," Nature, 2001, 409 (6822), 860-921.

Marshall, Eliot, "NIH to produce a 'working draft' of the genome by 2001," Science, 1998, 281 (5384), 1774-1775.

_ , "Bermuda Rules: Community spirit, with teeth," Science, 2001, 291 (5507), 1192.

Merges, Robert and Richard Nelson, "On the complex economics of patent scope," Columbia Law Review, 1990, 90 (4), 839-916.

Moon, Seongwuk, "How does the management of research impact the disclosure of knowledge? Evidence from scientific publications and patenting behavior," Economics of Innovation and New Technology, 2011, 20 (1), 1-32.

Murray, Fiona and Scott Stern, "Do formal intellectual property rights hinder the free flow of scientific knowledge? An empirical test of the anti-commons hypothesis," Journal of Economic Behavior and Organization, 2007, 63 (4), 648-687.

_, Philippe Aghion, Mathias Dewatripont, Julian Kolev, and Scott Stern, "Of mice and academics: Examining the effect of openness on innovation," 2008. unpublished MIT mimeo.

National Academy of Sciences, Reaping the Benefits of Genomic and Proteomic Research: Intellectual Property Rights, Innovation, and Public Health, National Academies Press, 2006.

Nelson, Richard, "The simple economics of basic scientific research," Journal of Political Economy, 1959, 67 (3), 297-306.

Pennisi, Elizabeth, "Human genome: Academic sequencers challenge Celera in a sprint to the finish," Science, 1999, 283 (5409), 1822-1823.

Scherer, Stewart, A Short Guide to the Human Genome, Cold Spring Harbor Laboratory Press, 2008.

Science Online, "Accessing the Celera human genome sequence data," 2001. http://www.sciencemag . org/feature/data/announcement/gsp.dtl (last accessed 21 December 2011).

Scotchmer, Suzanne, "Standing on the shoulders of giants: Cumulative research and the patent law," Journal of Economic Perspectives, 1991, 5 (1), 29-41.

Service, Robert, "Can data banks tally profits?," Science, 2001, 291 (5507), 1203.

Shapiro, Carl, "Navigating the patent thicket: Cross licenses, patent pools, and standard setting," in Adam Jaffe, Josh Lerner, and Scott Stern, eds., Innovation Policy and the Economy Volume 1, MIT Press, 2000.

Shreeve, James, The Genome War: How Craig Venter Tried to Capture the Code of Life and Save the World, Ballantine Books, 2005.

Snyder, Michael and Mark Gerstein, "Defining genes in the genomics era," Science, 2003, 300 (5617), 258-260.

Sulston, John and Georgina Ferry, The Common Thread: Science, Politics, Ethics, and the Human Genome, Corgi Books, 2002.

Uhlmann, Wendy and Alan Guttmacher, "Key internet genetics resources for the clinician," Journal of the American Medical Association, 2008, 299 (11), 1356-1358. 
US National Human Genome Research Institute (NHGRI), US National Institutes of Health (NIH), "NHGRI policy regarding intellectual property of human genomic sequence: Policy on availability and patenting of human genomic DNA sequence produced by NHGRI pilot projects (funded under RFA HG-95-005)," 1996. http://www.genome.gov/10000926 (last accessed 21 December 2011).

Venter, J. Craig, "Prepared statement of J. Craig Venter, Ph.D. President and Chief Scientific Officer Celera Genomics, a PE Corporation Business before the Subcommittee on Energy and Environment, U.S. House of Representatives Committee on Science," 2000. http://clinton4.nara.gov/WH/EOP/ OSTP/html/00626_4.html (last accessed 21 December 2011).

_, A Life Decoded: My Genome, My Life, Viking Adult, 2007.

_ et al., "The sequence of the human genome," Science, 2001, 291 (5507), 1304-1351.

_, Mark Adams, Granger Sutton, Anthony Kerlavage, Hamilton Smith, and Michael Hunkapiller, "Shotgun sequencing of the human genome," Science, 1998, 280 (5369), 1540-1542.

Wade, Nicholas, "Once again, scientists say human genome is complete," New York Times, 2003, 15 April.

Walsh, John, Charlene Cho, and Wesley Cohen, "View from the bench: Patents and material transfers," Science, 2005, 309 (5743), 2002-2003.

_, Wesley Cohen, and Charlene Cho, "Where excludability matters: Material versus intellectual property in academic biomedical research," Research Policy, 2007, 36 (8), 1184-1203. 
Table 1: Innovation Outcomes for Celera \& non-Celera Genes Sequenced in 2001

\begin{tabular}{rcccc}
\hline & $(1)$ & $(2)$ & $(3)$ & $(4)$ \\
& $\begin{array}{c}\text { Celera } \\
\text { mean }\end{array}$ & $\begin{array}{c}\text { Non-Celera } \\
\text { mean }\end{array}$ & $\begin{array}{c}\text { difference } \\
{[(1)-(2)]}\end{array}$ & $\begin{array}{c}p \text {-value of } \\
\text { difference }\end{array}$ \\
\hline publications in 2001-2009 & 1.239 & 2.116 & -0.877 & {$[0.000]$} \\
$\mathbf{1}$ (known, uncertain phenotype) & 0.401 & 0.563 & -0.162 & {$[0.000]$} \\
$\mathbf{1}$ (known, certain phenotype) & 0.046 & 0.073 & -0.027 & {$[0.000]$} \\
$\mathbf{1}$ (used in any diagnostic test) & 0.030 & 0.054 & -0.024 & {$[0.000]$} \\
\hline$N$ & 1,682 & 2,851 & & \\
\hline
\end{tabular}

Notes: This table compares subsequent innovation outcomes for Celera genes relative to non-Celera genes sequenced in the same year. Gene-level observations. Sample in Column (1) includes all Celera genes; sample in Column (2) includes all non-Celera genes sequenced in 2001. The $p$-value reported in Column (4) is from a $t$-test for a difference in mean outcomes across Column (1) and Column (2). See text and online appendix for more detailed data and variable descriptions.

Table 2: Summary Statistics for Gene-Level Data

\begin{tabular}{|c|c|c|c|c|c|}
\hline & mean & median & $\begin{array}{l}\text { standard } \\
\text { deviation }\end{array}$ & minimum & maximum \\
\hline \multicolumn{6}{|l|}{ Panel A: Sequencing \& Celera's IP } \\
\hline year sequence disclosed & 2002.962 & 2001 & 3.551 & 1999 & 2009 \\
\hline $\mathbf{1}($ Celera gene $)$ & 0.060 & 0 & 0.238 & 0 & 1 \\
\hline \multicolumn{6}{|l|}{ Panel B: Outcome variables } \\
\hline publications in 2001-2009 & 2.197 & 0 & 9.133 & 0 & 231 \\
\hline $\mathbf{1}$ (known, uncertain phenotype) & 0.453 & 0 & 0.498 & 0 & 1 \\
\hline $\mathbf{1}$ (known, certain phenotype) & 0.081 & 0 & 0.273 & 0 & 1 \\
\hline $\mathbf{1}$ (used in any diagnostic test) & 0.060 & 0 & 0.238 & 0 & 1 \\
\hline$N=27,882$ & & & & & \\
\hline
\end{tabular}

Notes: Gene-level observations. Note that the mean year of disclosure is affected by left-censoring since a disclosure year of 1999 represents a gene sequenced in or before 1999 (1999 is the earliest year any observations appear in the RefSeq database). See text and the online appendix for more detailed data and variable descriptions. 
Table 3: Cross-Section Estimates: Impact of Celera's IP on Innovation Outcomes
$(1)$
$(2)$
$(3)$

\begin{tabular}{|c|c|c|c|}
\hline \multicolumn{4}{|l|}{$\frac{\text { Panel A: publications in 2001-2009 }}{\text { mean }=2.197}$} \\
\hline celera & $\begin{array}{c}-0.877 \\
(0.177)^{* * *}\end{array}$ & $\begin{array}{c}-0.328 \\
(0.099)^{* * *}\end{array}$ & $\begin{array}{c}-0.264 \\
(0.107)^{* * *}\end{array}$ \\
\hline \multicolumn{4}{|l|}{ Panel B: 1(known, uncertain phenotype) } \\
\hline \multicolumn{4}{|l|}{ mean $=0.453$} \\
\hline celera & $\begin{array}{c}-0.162 \\
(0.015)^{* * *}\end{array}$ & $\begin{array}{c}-0.158 \\
(0.015)^{* * *}\end{array}$ & $\begin{array}{c}-0.128 \\
(0.017)^{* * *}\end{array}$ \\
\hline \multicolumn{4}{|l|}{ Panel C: 1(known, certain phenotype) } \\
\hline \multicolumn{4}{|l|}{ mean $=0.081$} \\
\hline celera & $\begin{array}{c}-0.027 \\
(0.007)^{* * *}\end{array}$ & $\begin{array}{c}-0.017 \\
(0.006)^{* * *}\end{array}$ & $\begin{array}{c}-0.014 \\
(0.007)^{* *}\end{array}$ \\
\hline \multicolumn{4}{|l|}{ Panel D: 1(used in any diagnostic test) } \\
\hline \multicolumn{4}{|l|}{ mean $=0.060$} \\
\hline celera & $\begin{array}{c}-0.023 \\
(0.006)^{* * *} \\
\end{array}$ & $\begin{array}{c}-0.014 \\
(0.005)^{* * *} \\
\end{array}$ & $\begin{array}{c}-0.013 \\
(0.006)^{* *}\end{array}$ \\
\hline indicator variables for year of disclosure & yes & yes & yes \\
\hline number of publications in each year $1970-2000$ & no & yes & yes \\
\hline detailed cytogenetic \& molecular covariates & no & no & yes \\
\hline$N$ & 27,882 & 27,882 & 16,485 \\
\hline
\end{tabular}

Notes: Gene-level observations. All estimates are from ordinary-least-squares (OLS) models. Samples in Columns (1) and (2) include all genes; sample in Column (3) includes all genes with non-missing cytogenetic and molecular covariates. Robust standard errors shown in parentheses. $*: p<0.10 ; * *: p<0.05 ; * * *: p<0.01$. "Celera": $0 / 1,=1$ for a Celera gene. Indicator variables for year of disclosure: 0/1 indicator variables for the year sequence for the gene was disclosed. Number of publications in each year 1970-2000: count variables for the number of publications on each gene in each year from 1970 to 2000. Detailed cytogenetic 8 molecular covariates: $0 / 1$ indicator variables for the chromosome $(1-22, X$, or $Y$ ) and arm $(p$ or $q)$ on which a gene is located; continuous variables for region, band, subband, start base pair, and end base pair; and 0/1 indicator variables for the orientation of the gene on the genome assembly (plus or minus). See text and the online appendix for more detailed data and variable descriptions. 
Table 4: Panel Estimates: Impact of Celera's IP on Innovation Outcomes

\begin{tabular}{|c|c|c|c|}
\hline & $(1)$ & $(2)$ & $(3)$ \\
\hline \multicolumn{4}{|l|}{ Panel A: publications } \\
\hline \multicolumn{4}{|l|}{ mean $=0.244$} \\
\hline celera & $\begin{array}{c}-0.160 \\
(0.017)^{* * *} \\
\end{array}$ & $\begin{array}{c}-0.121 \\
(0.011)^{* * *} \\
\end{array}$ & $\begin{array}{c}-0.109 \\
(0.011)^{* * *}\end{array}$ \\
\hline \multicolumn{4}{|l|}{ Panel B: 1(known, uncertain phenotype) } \\
\hline \multicolumn{4}{|l|}{ mean $=0.381$} \\
\hline celera & $\begin{array}{c}-0.163 \\
(0.009)^{* * *}\end{array}$ & $\begin{array}{c}-0.160 \\
(0.008)^{* * *}\end{array}$ & $\begin{array}{c}-0.083 \\
(0.008)^{* * *}\end{array}$ \\
\hline year fixed effects & yes & yes & yes \\
\hline indicator variables for year of disclosure & yes & yes & no \\
\hline number of publications in each year $1970-2000$ & no & yes & no \\
\hline gene fixed effects & no & no & yes \\
\hline$N$ & 250,938 & 250,938 & 250,938 \\
\hline
\end{tabular}

Notes: Gene-year-level observations. All estimates are from ordinary-least-squares (OLS) models. The sample includes all gene-years from 2001 to 2009 (27,882 genes for 9 years implies $N=250,938$ total gene-year observations). Robust standard errors, clustered at the gene level, shown in parentheses. ${ }^{*}: p<0.10 ;{ }^{* *}: p<0.05$; ***: $p<0.01$. "Celera": $0 / 1,=1$ for a Celera gene. Indicator variables for year of disclosure: 0/1 indicator variables for the year sequence for the gene was disclosed. Number of publications in each year 1970-2000: count variables for the number of publications on each gene in each year from 1970 to 2000. See text and online appendix for more detailed data and variable descriptions. 
Figure 1: Timeline of Key Events

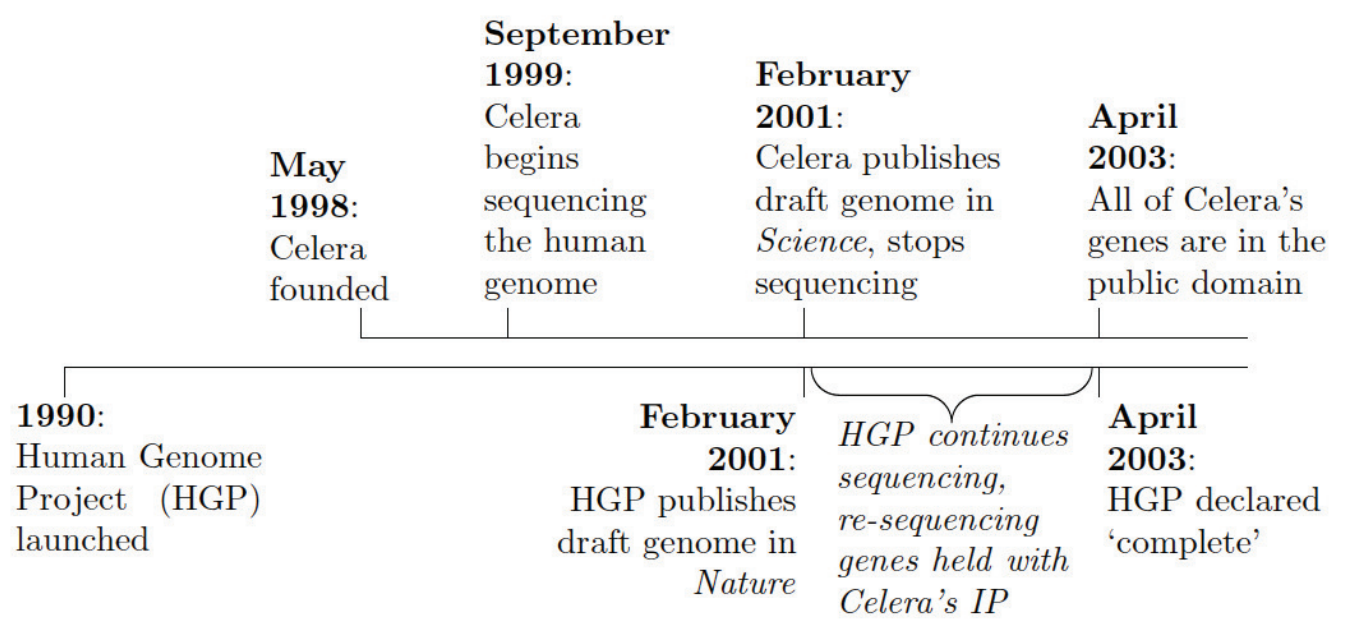

Notes: This figure summarizes the key events analyzed in this paper. For details, see Collins and Galas (1993), Venter et al. (1998), Venter (2000), Lander et al. (2001), Venter et al. (2001), and Wade (2003). 


\section{Figure 2: Documenting the Link Between Scientific Research \& Product Development}

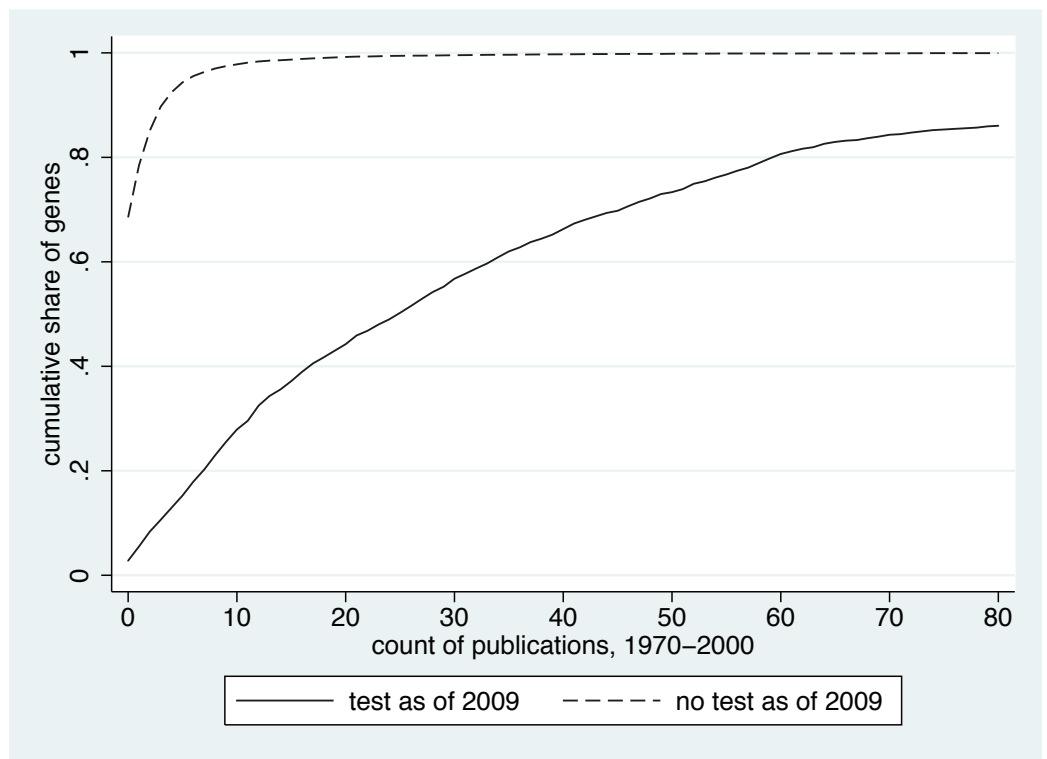

(a) CDF of number of publications for genes with/without a diagnostic test

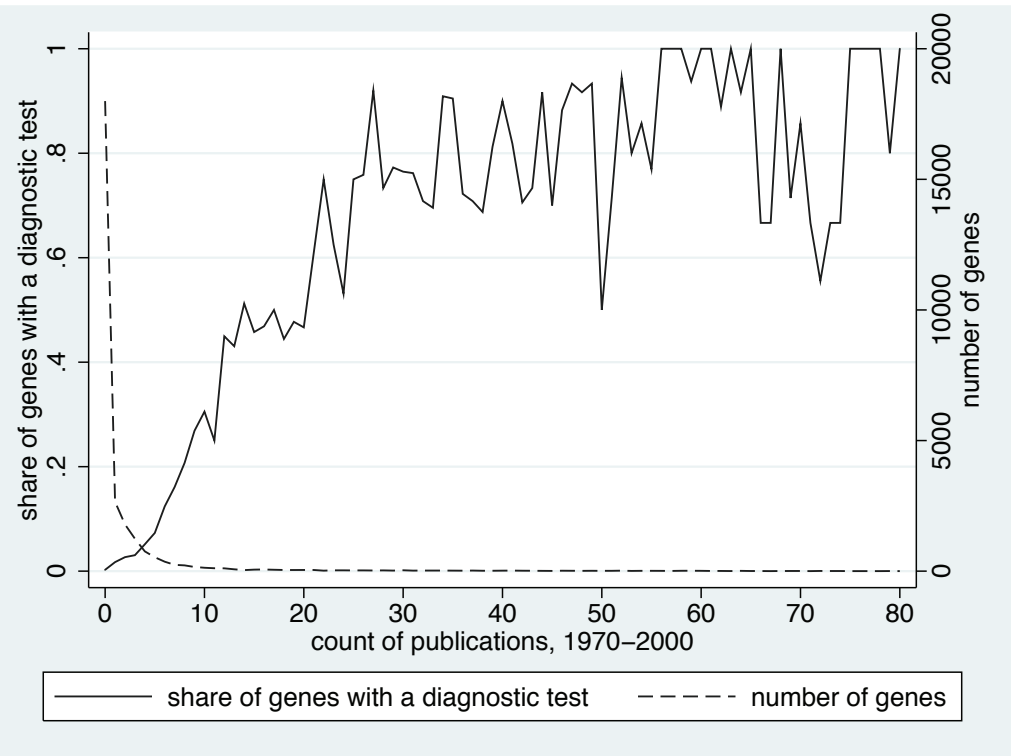

(b) Share of genes with a diagnostic test by number of publications

Notes: These figures provide two sets of descriptive statistics that document the link between scientific research and product development in my data. In sub-figure (a), the dashed line plots the empirical cumulative distribution function of the number of publications between 1970-2000 for genes that do not have a diagnostic test available as of 2009, and the solid line plots the empirical cumulative distribution function of the number of publications between 1970-2000 for genes that do have a diagnostic test available as of 2009. In sub-figure (b), the dashed line plots the distribution of genes by the number of publications between 1970-2000, and the solid line plots the share of genes with a diagnostic test as of 2009 at each number of publications. See text and online appendix for more detailed data and variable descriptions. 


\section{Figure 3: Investigating Selection into Celera's IP}

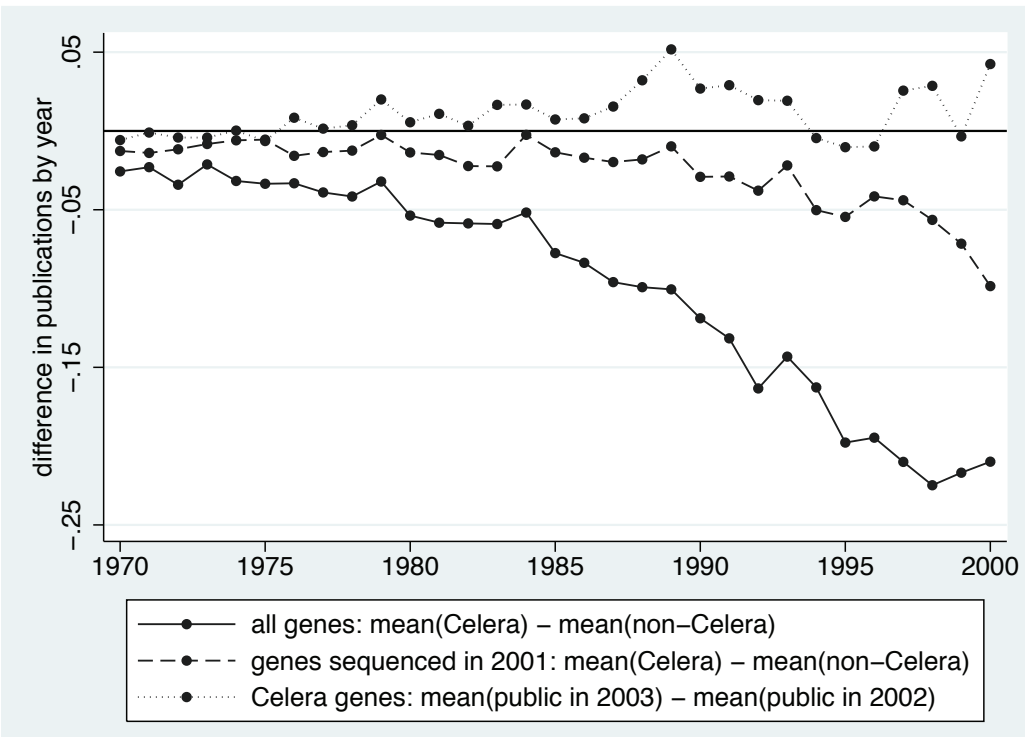

Notes: This figure provides three sets of descriptive statistics investigating the selection of genes into Celera's intellectual property (IP). The solid line ("all genes") plots the difference in mean publications on Celera genes and mean publications on non-Celera genes in each year from 1970 to 2000. The dashed line ("genes sequenced in 2001") plots the difference in mean publications on Celera genes and mean publications on non-Celera genes that were sequenced in 2001 in each year from 1970 to 2000. The dotted line ("Celera genes") plots the difference in mean publications on Celera genes resequenced in 2003 and mean publications on Celera genes resequenced in 2002 in each year from 1970 to 2000. See text and online appendix for more detailed data and variable descriptions. 
Figure 4: Panel Estimates: Impact of Celera's IP on Innovation Outcomes

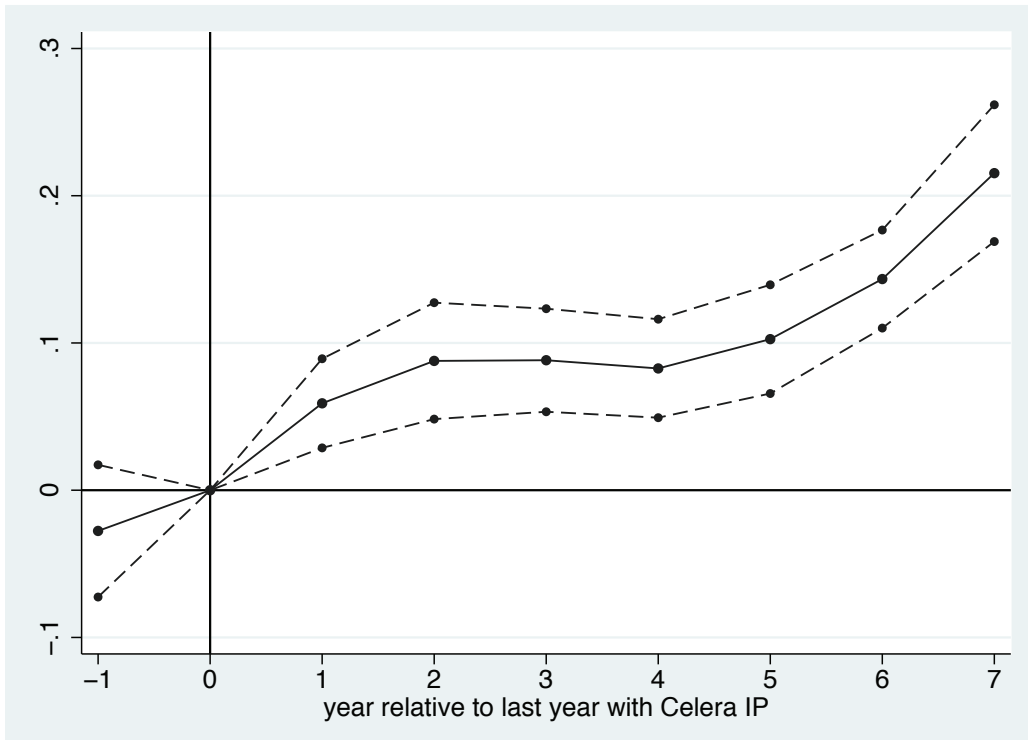

(a) Outcome variable: Publications

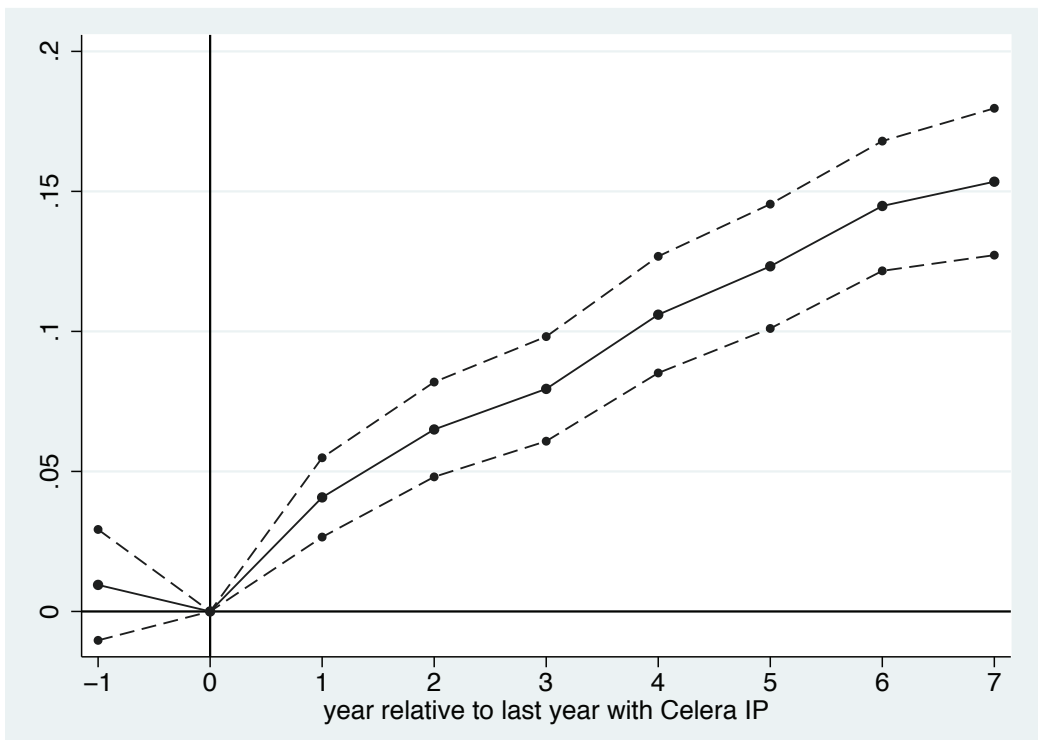

(b) Outcome variable: $\mathbf{1}($ known/uncertain phenotype)

Notes: These figures plot coefficients (and 95 percent confidence intervals) from the event study specification described in Section 3.2 . On the $x$ axes are years $z$ relative to a "zero" relative year that marks the last year the gene was held with Celera's IP (that is, year 1 marks the first year the gene was in the public domain). As in the specifications in Table 4 this specification is based on gene-year level observations, the coefficients are estimates from ordinary-least-squares (OLS) models, the sample includes all gene-years from 2001 to 2009 , and the standard errors are robust and clustered at the gene level. See text and online appendix for more detailed data and variable descriptions. 
Figure 5: Average Innovation Outcomes for Celera Genes by Year, by Year of Re-sequencing by the Public Effort

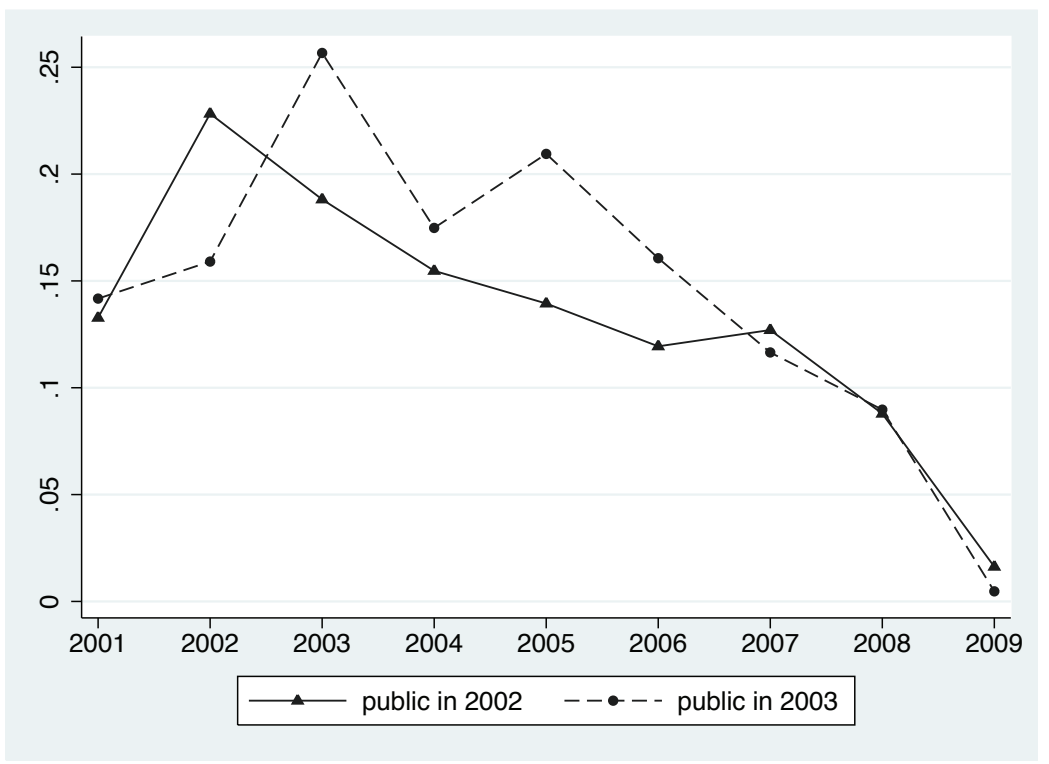

(a) Outcome variable: Publications

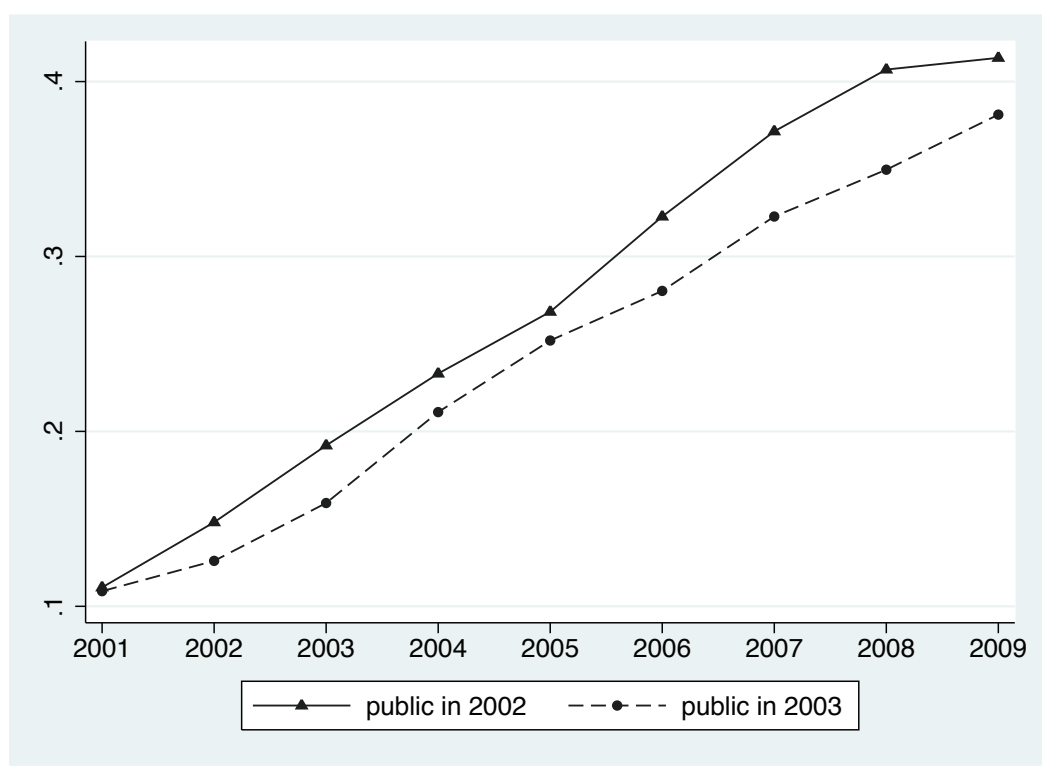

(b) Outcome variable: $\mathbf{1}($ known/uncertain phenotype)

Notes: These figures plot the descriptive statistics described in Section 3.3. Sample includes all Celera genes. Means are shown separately for Celera genes that were re-sequenced by the public effort in $2002(N=1,047)$ and for Celera genes that were re-sequenced by the public effort in $2003(N=635)$. See text and online appendix for more detailed data and variable descriptions. 


\section{Appendix A: Data description}

This appendix describes in additional detail the data sets used in my analysis.

Public sequencing data

I track the public sequencing effort at the mRNA-by-year level from 1999 forward using the online US National Institutes of Health's (NIH) RefSeq database $1^{1}$ The RefSeq database is maintained by the National Center for Biotechnology Information (NCBI), a division of the US NIH's National Library of Medicine (NLM). As described on its website, the RefSeq (Reference Sequence) database "... aims to provide a comprehensive, integrated, non-redundant, well-annotated set of sequences, including genomic DNA, transcripts, and proteins."

Each RefSeq record represents a naturally occurring molecule from one organism, and is identified by a distinct RefSeq accession-version number (e.g. NM_000646.1) that can be used to match RefSeq records with other databases. As noted above, RefSeq records are available for several types of molecules, including genomic DNA, transcripts, and proteins; the relevant molecule for a given RefSeq record is identifiable through the two prefix letters on the RefSeq number ${ }^{2}$ RefSeq records are available for many different organisms, including eukaryoktes, bacteria, and viruses; the relevant organism for a given RefSeq record is identifiable through the taxonomic ID number ${ }^{3}$ I focus on the human messenger RNA (mRNA) RefSeq records.

I use RefSeq release 34, which incorporates data available as of 6 March 2009. The catalog for RefSeq release 34 gives a list of accession/version numbers included in that database $4^{4}$ For each RefSeq accession/version number corresponding to a human mRNA transcript, I query (via a Python script) the online Sequence Revision History website to determine the date at which that record first appeared in the RefSeq database 5

It is important to note that the public sequencing efforts could be tracked in at least two other ways: using GenBank, another NCBI online database, or using genome assemblies. It is worth clarifying why I chose to track the public sequencing efforts through the RefSeq database, and what the advantages and disadvantages of these data are relative to the GenBank or genome assembly data.

GenBank is the "original" database to which individual laboratories submitted data under the Bermuda rules of the public sequencing effort, and in that sense is the most accurate measure of when a given section of DNA was sequenced by the public effort. Unfortunately, several characteristics of the GenBank data complicate its usefulness for this analysis. As described on the US Department of Energy website, GenBank is an "archival" database, containing records created by individual scientists. ${ }^{6}$ Because of this, GenBank may contain hundreds of records documenting the same mRNA transcript. Unfortunately, no identification numbers exist that can link a GenBank record for a given mRNA transcript either to other GenBank records for the same mRNA transcript, or to other databases. Moreover, because there is no independent review

\footnotetext{
${ }^{1}$ Available at http://www.ncbi.nlm.nih.gov/RefSeq/ (last accessed 21 December 2011). See also Pruitt, Tatusova and Maglott (2007).

${ }^{2}$ The prefix letters for mRNA records are NM, NR, XM, and XR; see ftp://ftp.ncbi.nih.gov/refseq/ release/release-notes/archive/RefSeq-release34.txt (last accessed 21 December 2011).

'The taxonomic ID number for humans is 9606; see http://www.ncbi.nlm.nih.gov/Taxonomy/Browser/ wwwtax.cgi?mode=Undef\&name=Homo+sapiens\&lvl=0\&srchmode=1 (last accessed 21 December 2011).

${ }^{4}$ Available at ftp://ftp.ncbi.nih.gov/refseq/release/release-catalog/archive/RefSeq-release34. catalog.gz (last accessed 21 December 2011).

${ }^{5}$ Available at http://www.ncbi.nlm.nih.gov/entrez/sutils/girevhist.cgi (last accessed 21 December 2011). I am very grateful to David Robinson for assistance in writing this script.

${ }^{6}$ See http://www.ornl.gov/sci/techresources/Human_Genome/posters/chromosome/sequence.shtml (last accessed 21 December 2011).
} 
system for sequence data submitted to GenBank, the data may contain errors. The RefSeq database was created specifically to overcome these shortcomings of the GenBank database that complicated its use by researchers in many contexts. Many RefSeq records are derived from GenBank records, but RefSeq aims to provide non-redundant records that identify molecules by unique identification numbers, and that undergo a review process to screen for problems such as sequencing errors. RefSeq also includes some data not submitted to GenBank but available elsewhere (such as in published papers). The US Department of Energy website cited above notes, "Since RefSeq records undergo a review process that screens for problems such as sequencing errors and vector contamination, RefSeq records are good sources of sequence information." Although I have no systematic way of comparing dates of accession to GenBank with dates of accession to RefSeq, based on some hand-checks it appeared that (as expected) sequences appearing in RefSeq at earlier dates tended to be based on sequences that appeared in GenBank at earlier dates, with a relatively short lag. In sum, I rely on RefSeq records rather than GenBank records because RefSeq records identify unique mRNA observations with identification numbers that can be reliably matched to other databases, because scientists appear to rely on the RefSeq database as a source of sequencing data, and because based on some hand-checks dates of accession to RefSeq appear correlated with dates of accession to GenBank.

The second alternative would be to track the inclusion of mRNAs in NCBI's genome assemblies, which were released approximately annually over my time period of interest. Using the date an mRNA was first included in an NCBI genome assembly as the measure of the date of public sequencing could be more appropriate than the RefSeq measure if scientists primarily relied on the genome assemblies rather than the underlying mRNA transcript-level data. In practice, for the one assembly that I can easily compare these two measures they appear to be quite similar. Specifically, comparing the mRNA transcripts included in the NCBI-34 genome assembly from 2003 with the set of mRNA transcripts included in the RefSeq data as of 2003 suggests a relatively close correspondence: no mRNA transcripts were included in NCBI-34 but not included in the RefSeq data, and approximately 1,206 mRNA transcripts were included in RefSeq but not included in the NCBI-34 assembly (relative to 27,348 mRNA transcripts included in both datasets) 7 Relying on the RefSeq records rather than the genome assembly data is also preferable because the latter would require me to run analyses to compare various versions of the human genome assemblies, a task that is feasible but requires a relatively high level of scientific expertise. In sum, I rely on RefSeq records rather than comparisons of genome assemblies for computational ease, and because one comparison of the two measures suggested a close correspondence.

Celera sequencing data

For the private sector effort, there was essentially only one "version" of data, which I refer to as the Celera data. Comparing the Celera data with the public sequence data at a given point in time itself requires a non-trivial scientific analysis. Fortuitously for this work, a 2004 publication (Istrail et al., 2004) performed just such a comparison, and based on this analysis I am able to construct an mRNA-by-year level variable for whether a given mRNA transcript was included in the Celera data but had not yet appeared in the public sequencing data.

Specifically, Istrail et al. (2004) compare the Celera whole genome shotgun assembly (WGSA) as of December 2001 with the NCBI-34 (Build 34, October 2003) release of the public sector human genome assembly. Table 6 in Istrail et al. (2004) gives a list of RefSeq numbers for which

\footnotetext{
${ }^{7}$ One reason why an mRNA transcript may be included in the RefSeq data but not in the NCBI-34 assembly is if the transcript was sequenced but it was not clear where the transcript "fit" in terms of its location on the full human genome assembly.
} 
the RefSeq mapping was longer in WGSA relative to NCBI-34, and Table 7 in Istrail et al. (2004) gives an analogous list of RefSeq numbers for which the RefSeq mapping was longer in NCBI-34 relative to WGSA.

I obtained an archived version of the mRNA transcripts included in NCBI-34 from the NCBI website (downloaded 27 April 2009), and used a Python script to extract the RefSeq numbers for each mRNA transcript in these data 8 Three RefSeq IDs in this list were duplicates, and I drop one of each duplicate set. Matching this list to the RefSeq release 34 data described above, some records are included in NCBI-34 but not in RefSeq release 34 (largely "suspended" records), and some records are included in RefSeq release 34 but not in NCBI-34 (as expected, since RefSeq release 34 is a more recent dataset). I discard records in either NCBI-34 or in WGSA that are linked to mRNA transcripts listed in RefSeq release 34 as "suspended" records.

Table 6 of Istrail et al. (2004) lists RefSeq numbers for which the RefSeq mapping was longer in WGSA relative to NCBI-34, but this measure of length can be a fraction less than one - which would imply that a given mRNA transcript was partially but not entirely included in the NCBI34 data. To be conservative, I define an mRNA transcript as being in the public domain if any part of the transcript was in the public domain according to the analysis of Istrail et al. (2004). Substantively, this means that I consider all RefSeq numbers listed in Table 6 of Istrail et al. (2004) to be in the public domain if any fraction of the transcript was in NCBI-34. Only four RefSeq numbers listed in Table 6 of Istrail et al. (2004) are listed as having been completely absent from the NCBI-34 data, and all four of these RefSeq numbers are listed in the RefSeq release 34 data as "suspended" records. Thus, for the purposes of my analysis there are no RefSeq numbers that were in the WGSA data but not in NCBI-34.

I construct an mRNA-by-year level variable for whether a given mRNA transcript was included in the Celera data but had not yet appeared in the public sequencing data as of 2001 as follows. Let A represent the RefSeq numbers in NCBI-34 but not in WGSA; let B represent the RefSeq numbers in both NCBI-34 and in WGSA; and let C represent the RefSeq numbers in WGSA but not in NCBI-34. Table 7 in Istrail et al. (2004) gives me the set A, and as noted above by my definition the set $\mathrm{C}$ has no elements. Together with the full NCBI-34 dataset described above, I can thus construct B as (NCBI-34) minus A. Some elements of B were in the set $\mathrm{B}$ as of 2001 , whereas other elements of B were sequenced by the public effort sometime after 2001 and before the October 2003 NCBI-34 release. Because I wish to identify those mRNA transcripts that were only included in the Celera version of the human genome as of December 2001, I want to subtract off those elements of B that were added to the public database after December 2001. At the mRNA-year level, I thus create a 0/1 Celera variable, equaling one for observations in the following set:

B - ( b $\in$ B | b first appearing in RefSeq after December 2001) + C

OMIM database: Publications and scientific knowledge outcome variables

I draw several gene-level outcome variables from the Online Mendelian Inheritance in Man (MIM, or OMIM), database $?^{9}$

A paper version of MIM was initially created in the 1960s by Dr. Victor McKusick as a catalog of Mendelian traits and disorders. Twelve paper editions were published between 1966 and 1998. The online version, OMIM, was created in 1985 by a collaboration between the

\footnotetext{
${ }^{8}$ Available at ftp://ftp.ncbi.nih.gov/genomes/H_sapiens/ARCHIVE/BUILD.34.1/RNA/rna.gbk.gz (last accessed 21 December 2011).

${ }^{9}$ Available at http://www.ncbi.nlm.nih.gov/sites/entrez?db=omim (last accessed 21 December 2011). See also McKusick-Nathans Institute of Genetic Medicine, Johns Hopkins University (Baltimore, MD).
} 
National Library of Medicine and the William H. Welch Medical Library at Johns Hopkins, and first became available on the internet in 1987. OMIM is currently authored and edited at the McKusick-Nathans Institute of Genetic Medicine at the Johns Hopkins University School of Medicine.

As described on its website, OMIM aims to provide a "comprehensive, authoritative, and timely compendium of human genes and genetic phenotypes" (a phenotype is an observable characteristic or trait of an organism). OMIM is updated daily, and is intended for use by physicians and other professionals concerned with genetic disorders, as well as genetics researchers.

OMIM includes six types of records:

- Genes of known sequence (indicated with an asterisk * preceding the MIM number);

- Descriptive entries, usually of phenotypes, that do not represent a unique locus on the human genome (indicated with a number symbol \# preceding the MIM number);

- Descriptions of a gene of known sequence and phenotype (indicated with a plus sign + preceding the MIM number);

- Descriptions of a confirmed mendelian phenotype for which the underlying molecular basis is not known (indicated with a percent sign \% preceding the MIM number);

- Descriptions of phenotypes with a suspected but unconfirmed mendelian basis, or with separateness from a phenotype in another OMIM entry that is unclear (indicated with the lack of a symbol preceding the MIM number);

- Removed records (indicated with a caret symbol ^ preceding the MIM number).

I create a "known, uncertain phenotype" indicator variable for whether a gene appears in any of these types of records, as a proxy for the gene being thought to be related to a given phenotype with some (potentially low) level of scientific certainty. I create a "known, certain phenotype" indicator variable for a gene appearing in either the second or the third type of OMIM records listed above, as a proxy for the gene being thought to be related to a given phenotype with a higher level of scientific certainty. OMIM records cite published scientific papers relevant for each record, which I collect as an additional outcome variable.

These OMIM outcome variables are collected in a cross-section (in 2009), but for two of the outcome variables, I am able to construct gene-by-year measures for use in the panel specification. First, I use paper publication dates to construct the number of publications by gene by year. Second, and less straightforward, I construct the first date each "known, uncertain phenotype" link appears in OMIM. I observe this latter measure with error, but expect this error to be uncorrelated with the Celera IP treatment variable. Specifically, the measurement error arises because OMIM includes entries of some phenotypes with unknown genotypes, some of which transition to become entries of phenotypes with known genotypes over time, and I do not observe these transition dates but rather observe the initial date any part of the entry appeared in OMIM. For example, Huntington's disease was known to be a genetic disease prior to the sequencing of the HTT gene, and my measurement of this date would likely capture the first date Huntington's disease was included in the OMIM database rather than the date when the sequenced gene allowed the full genotype-phenotype link to be listed in OMIM.

Each OMIM record includes a distinct MIM number (e.g. +611082), which can be used to match OMIM records with other databases. One gene can be included in more than one OMIM record, and one OMIM record can involve more than one gene; I collapse the OMIM data to the gene level. For the measures of genotype-phenotype links, I take the maximum of indicator 
variables by gene, and for the publications measure I sum the total number of publications relevant to that gene from all OMIM entries.

I use the full-text OMIM version of 19 April 2009 and extract, via a Python script, the outcome variables described above for each OMIM record in this text file 10

GeneTests.org database: Diagnostic test availability outcome variable

I draw a gene-level indicator for the availability of any genetic test related to that gene from the US NIH's GeneTests.org online database ${ }^{11}$

As described on its website, GeneTests.org includes a laboratory directory that is a selfreported, voluntary listing of US and international laboratories offering in-house molecular genetic testing, specialized cytogenetic testing, and biochemical testing for inherited disorders. US-based laboratories listed in GeneTests.org must be certified under the Clinical Laboratory Improvement Amendment (CLIA) of 1988, which requires laboratories to meet quality control and proficiency testing standards; there are no such requirements for non-US-based laboratories.

The GeneTests.org website clarifies several types of information not included in its laboratory directory, including genetic testing on the diagnosis and/or monitoring of solid tumors, hematologic malignancies, infectious diseases, and forensic testing.

As described on its website, GeneTests.org aims to provide "current, authoritative information on genetic testing and its use in diagnosis, management, and genetic counseling" to promote "the appropriate use of genetic services in patient care and personal decision making." Originally based at the University of Washington in Seattle, GeneTests.org has been funded by a series of federal grants and is currently hosted at the US National Institutes of Health's National Center for Biotechnology Information (NCBI).

I use the GeneTests.org data as of 27 May 2009, which lists OMIM numbers for which there is any genetic test available in the GeneTests.org directory ${ }^{12}$ As with the OMIM data described above, one gene can be included in more than one OMIM record, and one OMIM record can involve more than one gene; I collapse the GeneTests.org data to the gene level, taking the maximum of this indicator variable by gene.

Gene-level covariates: Cytogenetic and molecular location variables

I draw several gene-level variables describing the location of a particular gene on the human genome from the US NIH's Entrez Gene database ${ }^{13}$

Geneticists use two types of variables to describe a gene's location on the human genome: cytogenetic location and molecular location ${ }^{14}$ Cytogenetic variables take forms such as $19 q 13.4$. For this example, 19 represents the chromosome on which the gene is located $(1-22, X$, or $Y$ ). The letter $q$ represents the arm of the chromosome on which the gene is located; each chromosome is divided into two arms based on the location of a narrowing called the centromere - a shorter $\operatorname{arm}(p)$ and a longer arm $(q)$. The numbers after the arm letter describe the position of the

\footnotetext{
${ }^{10}$ The current full-text OMIM version is available at ftp://ftp.ncbi.nih.gov/repository/OMIM/ARCHIVE/ omim.txt.Z (last accessed 21 December 2011). I am very grateful to David Robinson for assistance in writing this script.

${ }^{11}$ Available at http://www.ncbi.nlm.nih.gov/sites/GeneTests/?db=GeneTests (last accessed 21 December 2011). See also University of Washington, Seattle (2009).

${ }^{12}$ The current GeneTests.org data are available at ftp://ftp.ncbi.nih.gov/pub/GeneTests/disease_OMIM. txt (last accessed 21 December 2011).

${ }^{15}$ Available at ftp://ftp.ncbi.nih.gov/gene/ (last accessed 21 December 2011). See also Maglott et al. (2005).

${ }^{14}$ The data description in this section draws heavily on the discussion in http://ghr.nlm.nih.gov/handbook/ howgeneswork/genelocation (last accessed 21 December 2011).
} 
gene on the $p$ or $q$ arm, usually designated by two digits (representing a region and a band) and sometimes followed by a decimal point and one or more additional digits (representing sub-bands). These numbers increase with distance from the centromere.

Molecular location variables are in a sense more precise than cytogenetic location variables in that they describe a gene's location in terms of base pairs. For example, according to the NIH's National Center for Biotechnology Information (NCBI) database, the APOE gene on chromosome 19 begins with base pair 50,100,901 and ends with base pair 50,104,488. Together, these variables communicate both the precise position of the gene and the size of the gene (3,588 base pairs). However, different databases often present slightly different values for these variables.

I use two Entrez Gene files from 18 June 2009: the gene2refseq file and the gene_info file. ${ }^{15}$

From the gene2refseq file, I extract continuous variables for the start and end base pairs of the gene on the genomic accession (as well as indicator variables for uncertain start and end base pair data) and for the orientation of the gene on the genomic accession (plus and minus, as well as an indicator variable for uncertain orientation data). The gene2refseq observations are at the mRNA-level (identified by RefSeq accession/version numbers), but can include more than one observation for a given mRNA. I collapse this data to the gene level, taking the mean of each variable over all available observations.

From the gene_info file, I extract indicator variables for the chromosome on which the gene is located (1-22, $X, Y$, and an indicator for uncertain chromosome data), indicator variables for the arm of the chromosome on which the gene is located ( $p, q$, and an indicator for uncertain arm data), and continuous variables for the region, band, and subband position of the gene on the relevant arm (as well as indicator variables for uncertain region, band, or subband data). ${ }^{16}$

Other gene-level covariates: Disclosure dates

Using data already described above, I construct an additional set of gene-level covariates that a priori are likely to affect the amount of research conducted on a given gene: namely, indicator variables for the year sequence data for the gene was first disclosed.

Genes sequenced earlier have been "at risk" for research based on the sequenced data for a longer period of time, which I would expect to affect the total amount of research observed as of 2009. I define the date of sequence data disclosure as the minimum of (1) the first year I observe the sequence data in the RefSeq database; and (2) 2001, if the sequence data were included in the Celera data. Note that this minimum is taken over all mRNA transcripts for each gene, so measures the earliest date at which sequence data for any mRNA transcript on each gene was disclosed. I chose to use this disclosure date because of a concern that disclosure dates for other mRNA transcripts on a gene may be endogenous to the Celera IP treatment variable of interest.

RefSeq-to-gene and gene-to-OMIM crosswalks

I use NCBI-generated crosswalks to match RefSeq accession/version numbers to Entrez Gene ID numbers and to match Entrez Gene ID numbers to OMIM numbers 17

\footnotetext{
${ }^{15}$ The current versions of these two databases are available at ftp://ftp.ncbi.nih.gov/gene/DATA/ gene2refseq.gz and ftp://ftp.ncbi.nih.gov/gene/DATA/gene_info.gz (last accessed 21 December 2011).

${ }^{10}$ I made eight hand-corrections to the chromosome variable based on redundant information provided in the map location variable, and one hand-correction to the region variable - changing a zero region value (which only appeared once in the data) to an uncertain region value.

${ }^{17}$ Available at ftp://ftp.ncbi.nih.gov/refseq/release/release-catalog/archive/RefSeq-release34. catalog.gz and at ftp://ftp.ncbi.nih.gov/gene/DATA/mim2gene respectively (last accessed 21 December 2011).
} 


\section{Appendix B: Proportional models for cross-section estimates}

This appendix investigates the robustness of the estimates in Table 3 to using proportional models: quasi-maximum likelihood (QML) Poisson models for publications, and logit models for the binary outcomes. For the logit models, I report average marginal effects.

In Panel B, whenever the outcome variable (known, uncertain phenotype) equals zero there are also zero publications in the years 1970-2000, implying that these covariates cannot be included in the logit model estimation - hence the missing coefficient estimates in Columns (2) and (4) 18 Because of this, I add an additional column which presents estimates that condition only on location covariates, and show estimates conditional on the publication covariates only for the other outcome variables. In addition, for two of the outcomes (known, certain phenotype and used in any diagnostic test) in Columns (3) and (4) the indicator variable for genes sequenced in 2008 perfectly predicts the outcome variables, resulting in 2,964 observations being dropped from the estimation $(16,485-13,521=2,964) 19$

For brevity, I focus on interpreting the magnitudes of the point estimates in Column (1), and on contrasting these magnitudes with those in Column (1) of Table 3. In the QML-Poisson models, Celera's IP is associated with about 40 percent fewer publications (calculated as $\left(e^{\beta}-\right.$ 1) - 100) - almost identical to the estimate in Table 3. The estimate in Panel B implies a 7.7 percentage point reduction in the probability of having a known, uncertain phenotype link, about half the magnitude of the analogous estimate in Table 3 (which was 16 percentage points). The estimate in Panel $\mathrm{C}$ implies a 2.8 percentage point reduction in the probability of having a known, certain phenotype link, almost identical to the magnitude of the analogous estimate in Table 3; but note that unlike in Table 3, this estimate is not statistically significant once the publication covariates are added. Finally, the estimate in Panel D implies a 2.5 percentage point reduction in the probability of a gene being used in any currently available diagnostic test, again almost identical to the magnitude of the analogous estimate in Table 3. As in in Table 3, the magnitude of the estimated coefficients declines as covariates are added, but for all outcome variables except Panel $\mathrm{C}$ (known, certain phenotype), each of the estimates in all columns is statistically significant at the 5 percent level.

\footnotetext{
${ }^{18}$ OMIM does not describe how this variable is coded, but it appears to be strongly related to the existence of publications: in my data, all observations without a known, uncertain phenotype have no publications as of 2009, and very few (19; less than 1\%) observations with a known, uncertain phenotype have no publications as of 2009.

${ }^{19}$ In the full sample, this is not the case: for example, three of the genes sequenced in 2008 have a known, certain phenotype link. However, each of these three genes have missing location covariates, so this issue is only relevant in the columns where the location covariates are included.
} 
Table B.1: Cross-Section Estimates:

Impact of Celera's IP on Innovation Outcomes, Proportional Models

\begin{tabular}{|c|c|c|c|c|}
\hline & (1) & $(2)$ & $(3)$ & $(4)$ \\
\hline \multicolumn{5}{|l|}{ Panel A: publications in 2001-2009 } \\
\hline \multicolumn{5}{|l|}{ mean $=2.197$} \\
\hline \multirow[t]{2}{*}{ celera } & -0.535 & -0.499 & -0.509 & -0.504 \\
\hline & $(0.117)^{* * *}$ & $(0.107)^{* * *}$ & $(0.136)^{* * *}$ & $(0.120)^{* * *}$ \\
\hline$N$ & 27,882 & 27,882 & 16,485 & 16,485 \\
\hline \multicolumn{5}{|l|}{ Panel B: 1(known, uncertain phenotype) } \\
\hline \multicolumn{5}{|l|}{ mean $=0.453$} \\
\hline \multirow[t]{2}{*}{ celera } & -0.077 & - & -0.068 & - \\
\hline & $(0.007)^{* * *}$ & & $(0.005)^{* * *}$ & \\
\hline$N$ & 27,882 & & 16,485 & \\
\hline \multicolumn{5}{|l|}{ Panel C: 1(known, certain phenotype) } \\
\hline \multicolumn{5}{|l|}{ mean $=0.081$} \\
\hline \multirow[t]{2}{*}{ celera } & -0.028 & -0.005 & -0.023 & -0.002 \\
\hline & $(0.006)^{* * *}$ & $(0.004)$ & $(0.004)^{* *}$ & $(0.003)$ \\
\hline$N$ & 27,882 & 27,882 & 13,521 & 13,521 \\
\hline \multicolumn{5}{|l|}{ Panel D: 1(used in any diagnostic test) } \\
\hline \multicolumn{5}{|l|}{ mean $=0.060$} \\
\hline \multirow[t]{2}{*}{ celera } & -0.025 & -0.008 & -0.022 & -0.006 \\
\hline & $(0.005)^{* * *}$ & $(0.004)^{* * *}$ & $(0.003)^{* *}$ & $(0.003)^{* *}$ \\
\hline$N$ & 27,882 & 27,882 & 13,521 & 13,531 \\
\hline \multirow{3}{*}{$\begin{array}{r}\text { indicator variables for year of disclosure } \\
\text { number of publications in each year 1970-2000 } \\
\text { detailed cytogenetic \& molecular covariates }\end{array}$} & yes & yes & yes & yes \\
\hline & no & yes & no & yes \\
\hline & no & no & yes & yes \\
\hline
\end{tabular}

Notes: Gene-level observations. Estimates in Panel A are from quasi-maximum likelihood Poisson models. Estimates in Panels B through D report average marginal effects from logit models. Samples in Columns (1) and (2) include all genes; sample in Columns (3) and (4) include all genes with non-missing cytogenetic and molecular covariates. Robust standard errors shown in parentheses. *: $p<0.10 ; * *: p<0.05 ; * * *: p<0.01$. "Celera": 0/1, =1 for a Celera gene. Indicator variables for year of disclosure: 0/1 indicator variables for the year sequence for the gene was disclosed. Number of publications in each year 1970-2000: count variables for the number of publications on each gene in each year from 1970 to 2000. Detailed cytogenetic \& molecular covariates: $0 / 1$ indicator variables for the chromosome $(1-22, X$, or $Y)$ and arm $(p$ or $q)$ on which a gene is located; continuous variables for region, band, subband, start base pair, and end base pair; and 0/1 indicator variables for the orientation of the gene on the genome assembly (plus or minus). In Panel B, whenever the outcome variable equals zero there are also zero publications in the years 1970-2000, implying that these covariates cannot be included in the logit model estimation - hence the missing coefficient estimates in Columns (2) and (4). For two of the outcomes (Panels C and D) in Columns (3) and (4) the indicator variable for genes sequenced in 2008 perfectly predicts the outcome variable, resulting in 2,964 observations being dropped from the estimation $(16,485-13,521=2,964)$. See text and the online appendix for more detailed data and variable descriptions. 


\section{References}

Istrail, Sorin et al., "Whole-genome shotgun assembly and comparison of human genome assemblies," Proceedings of the National Academy of Sciences, 2004, 101 (7), 1916-1921.

Maglott, Donna, Jim Ostell, Kim Pruitt, and Tatiana Tatusova, "Entrez Gene: Gene-centered information at NCBI," Nucleic Acids Research, 2005, 33 (Database issue), D54-D58.

McKusick-Nathans Institute of Genetic Medicine, Johns Hopkins University (Baltimore, MD) and National Center for Biotechnology Information, National Library of Medicine (Bethesda, MD), "Online Mendelian Inheritance in Man, OMIM (TM)," 2009. http://www.ncbi . nlm.nih.gov/omim/ (last accessed 21 December 2011).

Pruitt, Kim, Tatiana Tatusova, and Donna Maglott, "NCBI reference sequences (RefSeq): A curated non-redundant sequence database of genomes, transcripts, and proteins," Nucleic Acids Research, 2007, 35 (Database issue), D61-D65.

University of Washington, Seattle, "GeneTests: Medical Genetics Information Resource (database online), Copyright," 2009. http://www.genetests.org (last accessed 21 December 2011). 